\title{
Revisitando o Pronaf: velhos questionamentos, novas interpretações ${ }^{1}$
}

\author{
Catia Grisa², Valdemar João Wesz Junior ${ }^{3}$ e Vitor Duarte Buchweitz ${ }^{4}$
}

Resumo: Este artigo visa realizar uma atualização do desempenho do Pronaf no Brasil, aprofundando a discussão sobre o público beneficiário e as atividades financiadas. Para tanto, utiliza-se como principal fonte o Anuário Estatístico do Crédito Rural do Banco Central do Brasil (1999 a 2012), complementando-o com informações da Secretaria da Agricultura Familiar (SAF) do Ministério do Desenvolvimento Agrário (MDA), principalmente para os anos de 1996 a 1998. Os resultados apontam que, por um lado, o Pronaf mantém uma concentração de contratos e de recursos nos agricultores familiares mais capitalizados, produtores de commodities (principalmente milho, soja e café) e localizados na região Sul, Sudeste e Centro-Oeste, reforçando o seu forte viés produtivista. Mas, ao analisar espacialmente os dados, percebe-se o financiamento de uma variedade de cultivos nas diferentes regiões brasileiras. Em ternos regionais, a ampliação dos recursos e contratos totais tem sido superior nas regiões Nordeste e Norte. Apesar disso, ainda são públicos e regiões que, em termos absolutos, mantêm-se minoritárias no acesso ao Pronaf, apesar de concentraram a maior parte da agricultura familiar brasileira.

Palavras-chaves: Pronaf, políticas públicas, agricultura familiar, desenvolvimento rural.

Abstract: This paper aims at updating Pronaf's performance in Brazil, deepening the discussion about the beneficiary public and financed activities. The main source used for the analysis is the Statistical Yearbook of Rural Credit of Brazil's Central Bank (19992012), supplemented with information from the Family Farming Secretariat (SAF) of

1. Os autores agradecem as contribuições dos avaliadores anônimos da Revista de Economia e Sociologia Rural, bem como a leitura e as considerações de Joacir Rufino de Aquino e Cristiano Desconsi. Erros e omissões que persistirem na análise são de responsabilidade unicamente dos autores.

2. Universidade Federal de Pelotas (FAEM/UFPel). Professora no Programa de Pós-Gradução em Desenvolvimento Territorial e Sistemas Agroindustriais. Observatório de Políticas Públicas para a Agricultura (OPPA/CPDA/UFRRJ). Pesquisadora. E-mail: catiagrisa@yahoo.com.br

3. Universidade Federal da Integração Latino-Americana (Unila). Professor do Curso de Desenvolvimento Rural e Segurança Alimentar. Observatório de Políticas Públicas para a Agricultura (OPPA/CPDA/UFRRJ). Pesquisador. E-mail: jwesz@yahoo.com.br

4. Universidade Federal de Pelotas (FAEM/UFPel).Graduando em Agronomia. E-mail: vitordb@hotmail.com 
the Agrarian Development Ministry (MDA), mainly for the period from 1996 to 1998. The results show that Pronaf maintains a concentration of resources and contracts on more capitalized farmers, commodity producers (mainly corn, soybeans and coffee) located in the South, Southeast and Center-West in Brazil, reinforcing its strong productivity-based bias. However, on the other hand, when analyzing spatialized data, we find the funding for a variety of crops in different regions. In regional terms, the increase of the overall resources and contracts has been higher in the Northeast and North. Despite this expansion, these regions and public remain, in absolute terms, the minority accessing Pronaf despite amounting for most of Brazilian family farmers.

Key-words: Pronaf, public policies, family farming, rural development.

Classificação JEL: Q18.

\section{Introdução}

Criado em 1995, o Programa Nacional de Fortalecimento da Agricultura Familiar (Pronaf) marca o reconhecimento do Estado brasileiro à agricultura familiar. De programas regionais que pouco reconheciam a importância econômica da categoria social - tratados historicamente como produtores de subsistência, pequenos agricultores ou produtores de baixa renda -, os agricultores familiares passaram a dispor de uma política nacional destinada exclusivamente para eles. Como afirmaram Schneider, Cazella e Mattei (2004, p. 23), "o programa nasceu com a finalidade de prover crédito agrícola e apoio institucional aos pequenos produtores rurais que vinham sendo alijados das políticas públicas até então existentes e encontravam sérias dificuldades de se manter no campo". Tratava-se, com efeito, de um programa que articulava diversos instrumentos, como o crédito rural, o financiamento de infraestruturas e serviços básicos municipais (Pronaf Infraestrutura), e a capacitação e profissionalização dos agricultores familiares e demais atores relacionados com a categoria. Ainda que atualmente, após várias mudanças e reformulações, o Pronaf apresente-se basicamente como uma política de crédito rural - minimizando os outros instrumentos que também contribuiriam para promover o desenvolvimento rural - trata-se, provavelmente, da política agrícola de maior envergadura em termos de recursos financeiros disponibilizados e número de agricultores familiares beneficiários. Desde o início do Pronaf, têm sido crescentes os recursos aplicados, sendo que em 1996 foram destinados aproximadamente $\mathrm{R} \$$ 650 milhões e, em 2012, este montante alcançou quase $\mathrm{R} \$ 16$ bilhões (valores correntes), o que significa um crescimento superior a 20 vezes. No Plano Safra da Agricultura Familiar 2013/2014, o valor disponibilizado saltou para R\$ 21 bilhões (BRASIL, MDA, 2013).

Segundo as normas atualmente estabelecidas, podem acessar o Pronaf os agricultores que, simultaneamente, atendem os seguintes critérios: explorem parcela de terra na condição de proprietário, posseiro, arrendatário, comodatário, parceiro, concessionário do Programa Nacional de Reforma Agrária ou permissionário de áreas públicas; residam no estabelecimento ou em local próximo; não detenham área superior a quatro módulos fiscais; no mínimo $50 \%$ da renda bruta familiar seja originária da exploração agropecuária e não agropecuária do estabelecimento; tenham o trabalho familiar como predominante na exploração do estabelecimento, podendo contratar mão de obra sazonal ou manter empregados permanente em número menor que o número de pessoas da família ocupadas com o empreendimento familiar; e tenham obtido renda bruta familiar nos últimos 12 meses de até R\$ 360 mil reais (excluídos os benefícios sociais 
e os proventos previdenciários decorrentes de atividades rurais) (BRASIL, BANCO CENTRAL DO BRASIL, 2013). Estima-se que o Pronaf beneficia $40 \%$ dos agricultores familiares brasileiros (BRASIL, MDA, 2007) e está presente em 97\% dos municípios (DIEESE, 2011).

Pela importância política e expressão numérica do Pronaf, são recorrentes os estudos, pesquisas e avaliações sobre o mesmo. Em trabalho emblemático quando o programa completou 10 anos, Mattei (2006) identificou e catalogou 144 trabalhos técnicos e científicos realizados pelos mais diversos pesquisadores e analistas de políticas públicas do País, abordando diversas dimensões do Pronaf. Após 2006, uma miríade de estudos continuaram a ser realizados, a exemplo de Souza et al. (2013), Gazolla e Schneider (2013), Grisa (2012), Mattei (2011), Guanziroli (2009; 2007), Bianchini (2010), Delgado, Leite e Wesz Junior (2010) e Aquino e Schneider (2010). Nas vésperas de o programa completar 20 anos (2015) e no ensejo da definição de 2014 como o Ano Internacional da Agricultura Familiar, este artigo soma-se a estes trabalhos acadêmicos, visando realizar uma atualização da execução e do desempenho do Pronaf, aprofundando a discussão da relação que este programa estabelece com a diversidade socioeconômica dos agricultores familiares e com a diversidade produtiva brasileira. Para tanto, utiliza-se como principal fonte de dados o Anuário Estatístico do Crédito Rural do Banco Central do Brasil (1999 a 2012), complementando-o com informações da Secretaria da Agricultura Familiar (SAF) do Ministério do Desenvolvimento Agrário (MDA), principalmente para os anos de 1996 a 1998.

Para atender estes objetivos, o artigo foi estruturado em três seções, além desta introdução. A primeira discute alguns elementos que caracterizam os agricultores familiares que acessam o programa, especialmente no que concerne à localização geográfica e às condições socioeconômicas. A segunda seção debate as finalidades (custeio e investimento) e apresenta os principais produtos que são apoiados pelo Pronaf. Por fim, são retomadas algumas considerações sobre a discussão realizada.

\section{Os agricultores familiares do Pronaf: quem são e onde estão?}

Desde a criação do Pronaf, é perceptível o crescimento considerável do volume de recursos aplicados ao longo dos anos, que aumentaram de R\$ 650 milhões em 1996 para praticamente R\$ 16 bilhões em 2012. Conforme a Figura 1, a expansão mais acentuada ocorreu após o Governo Lula (incremento de 662\% no volume de recursos de 2002 a 2012), enquanto que de 1997 a 2002 mantinha-se uma estabilidade nos valores aplicados, com cifra próxima dos R 2 bilhões. Já o número total de contratos realizados no País apresentou movimento diferenciado para o mesmo intervalo de tempo (Figura 2), com valores crescentes até 2006, quando atingiu o número máximo de 2,5 milhões de contratos - período em que, como será discutido a seguir, houve maior participação da região Nordeste no número de contratos do Pronaf, em detrimento principalmente da participação relativa da região Sul. De 2008 a 2011, o número de contratos manteve-se próximo de 1,5 milhão, chegando, em 2012, a 1,8 milhão. Estimando a realização de um contrato por estabelecimento familiar, este número representaria cerca de $45 \%$ dos estabelecimentos familiares do Brasil em condições normativas de acessar o programa (IBGE, 2009).

Este cenário de expansão dos recursos aplicados pelo Pronaf se deve a um conjunto de mudanças, cabendo destacar, principalmente: i) a flexibilização das regras financeiras (redução da taxa de juros, expansão do prazo de pagamento, aumento do limite de recursos por contrato etc.); ii) mudanças institucionais no sentido de diversificar o público da agricultura familiar beneficiário (mulheres, jovens, ribeirinhos, extrativistas, indígenas, quilombolas, pescadores artesanais, grandes cooperativas etc.); iii) a diversificação das atividades econômicas apoiadas (Pronaf Agroindústria, Turismo Rural, Floresta, Agroecologia, Eco, Pesca etc.); iv) o aumento dos municípios abrangidos (que atingem mais de $97 \%$ atualmente); v) a simplificação das condições de acesso (redução de alguns entraves bancários, 
Figura 1. Recursos aplicados no Pronaf (R\$ - valores constantes) de 1996 a 2012 - Brasil

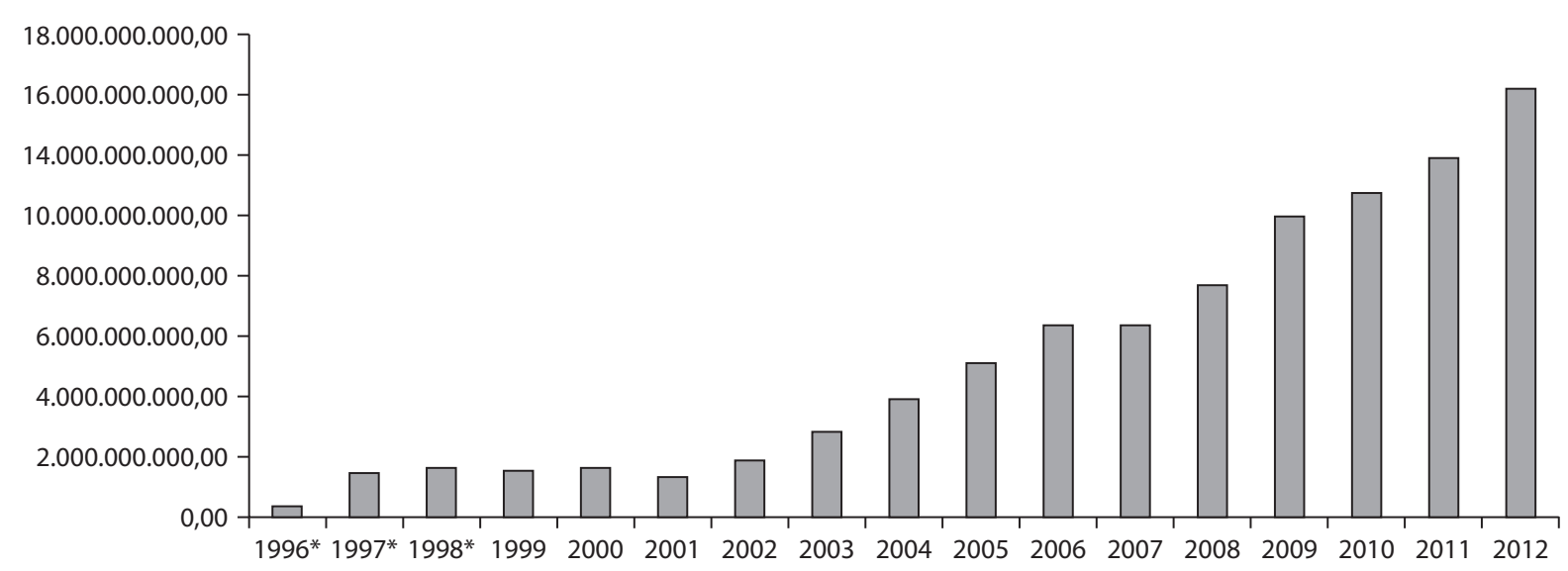

* MDA/SAF.

Fonte: Anuário Estatístico do Crédito Rural (vários anos) - Banco Central do Brasil.

Figura 2. Número de contratos do Pronaf de 1996 a 2012 - Brasil

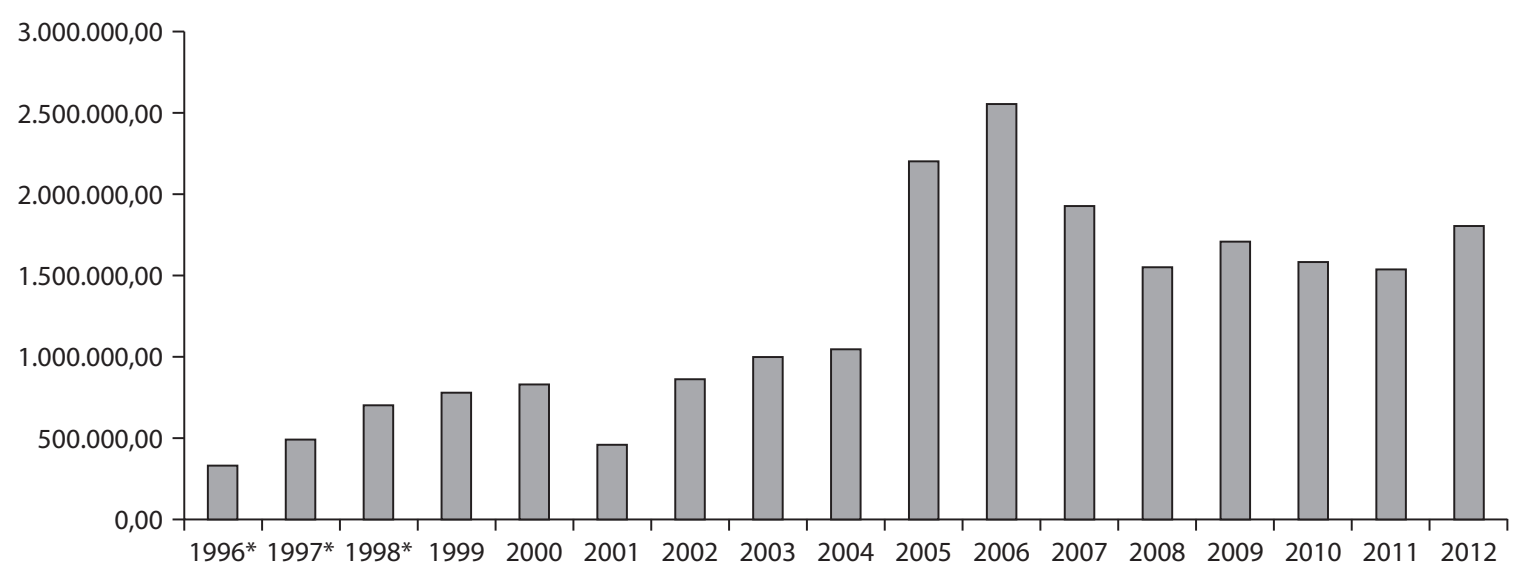

* MDA/SAF.

Fonte: Anuário Estatístico do Crédito Rural (vários anos) - Banco Central do Brasil.

maior facilidade de obtenção da Declaração de Aptidão ao Pronaf (DAP), eliminação da classificação por grupos de agricultores etc.); vi) o aumento da renda para fins de enquadramento dos agricultores no programa (a renda máxima para enquadramento atualmente no Pronaf é de R\$ 360 mil, ao passo que, no primeiro Plano Safra, era de R\$ 60 mil); vii) diversificação das fontes de financiamento, com crescente participação dos recursos obrigatórios (exigibilidades bancárias) e IHCD (Instrumento Híbrido de Capital e
Dívida), além do aumento da utilização de recursos dos Fundos Constitucionais; e viii) fortalecimento social e econômico da agricultura familiar nos últimos anos, exigindo maior relacionamento com as políticas públicas e com o sistema bancário (GRISA, 2012; MATTEI, 2011; DELGADO, LEITE e WESZ JUNIOR, 2010; GRISA e WESZ JUNIOR, 2010).

Em relação ao valor médio dos contratos, pode-se dizer que, entre 1996 e 2004, houve certa variação nos valores, com momentos de cres- 
cimento e redução, que não apontavam para uma tendência mais geral (Figura 3). Entretanto, isso muda a partir de 2005, quando ocorre um aumento ininterrupto dos valores até 2012, com ampliação de $240 \%$ neste período. É importante destacar que os valores mais baixos em 2005 e 2006 coincidem com o momento em que o número de contratos expandiu-se fortemente no Nordeste (Figura 4). Conforme a Figura 3, o valor médio dos contratos em 2012 alcançou R\$ 8.878,60, enquanto que, no início do programa, era de $\mathrm{R} \$$ 1.952,34 (valores correntes). Como será discutido, esta performance ao longo dos anos não é um dado banal, sinalizando para as possíveis características do público que acessa o Pronaf.

As Figuras 4 e 5 apresentam a distribuição dos recursos e dos contratos do Pronaf entre as grandes regiões brasileiras. Como observaram outros estudos (DELGADO, LEITE e WESZ JUNIOR, 2010; AQUINO e SCHNEIDER, 2010; MATTEI, 2006; 2005; TONNEAU, AQUINO e TEIXEIRA, 2005; SCHNEIDER, CAZELLA e MATTEI, 2004; BELIK, 2000; ABRAMOVAY e VEIGA, 1999), trata-se historicamente de uma incidência desproporcional do programa entre as regiões brasileiras, com prevalência massiva da participação da região Sul nos recursos aplicados e, não raro, também nos contratos efetuados.

Em termos de contratos do Pronaf, a região Sul respondia por $60 \%$ dos valores totais em 1998, enquanto que a região Nordeste participava com 25\%. Em 2005 e 2006, após várias avaliações e reivindicações sociais, estes percentuais praticamente inverteram-se e o Nordeste passou a responder por $60 \%$ dos contratos totais. Contudo, em anos seguintes, a região Sul ampliou novamente a sua participação, ainda que em percentuais mais baixos que no início da década de 2000. Em 2012, o Sul e o Nordeste responderam, respectivamente, por $32,74 \%$ e $45,48 \%$ dos contratos totais. As regiões Norte e Centro-Oeste participam com pequenos percentuais, sem nunca passar de $6 \%$ do total. A região Sudeste respondeu por percentual médio próximo dos 15\% no período considerado. Ao comparar estes números com a distribuição dos estabelecimentos da agricultura familiar entre as regióes brasileiras - sendo hegemônica a presença da agricultura familiar no Nordeste (50\%), seguida pelo Sul (19\%), Sudeste (16\%), Norte (10\%) e Centro-Oeste (5\%) (FRANÇA, DEL GROSSI e MARQUES, 2009) -, os desequilíbrios dos contratos do Pronaf ficam mais evidentes nas regiões Sul, Nordeste e Norte.

Figura 3. Valor médio dos contratos do Pronaf (R\$ - valores constantes) de 1996 a 2012 - Brasil

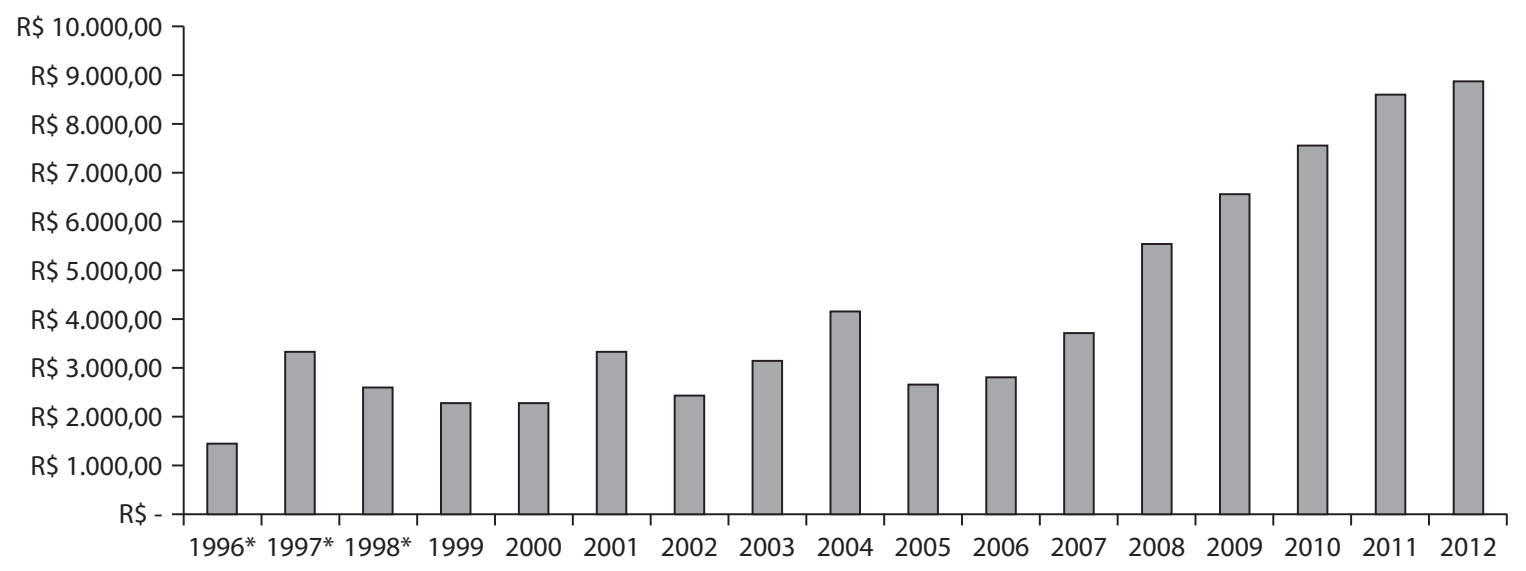

* MDA/SAF.

Fonte: Anuário Estatístico do Crédito Rural (vários anos) - Banco Central do Brasil. 
Figura 4. Distribuição dos contratos do Pronaf entre as grandes regiões brasileiras de 1996 a 2012

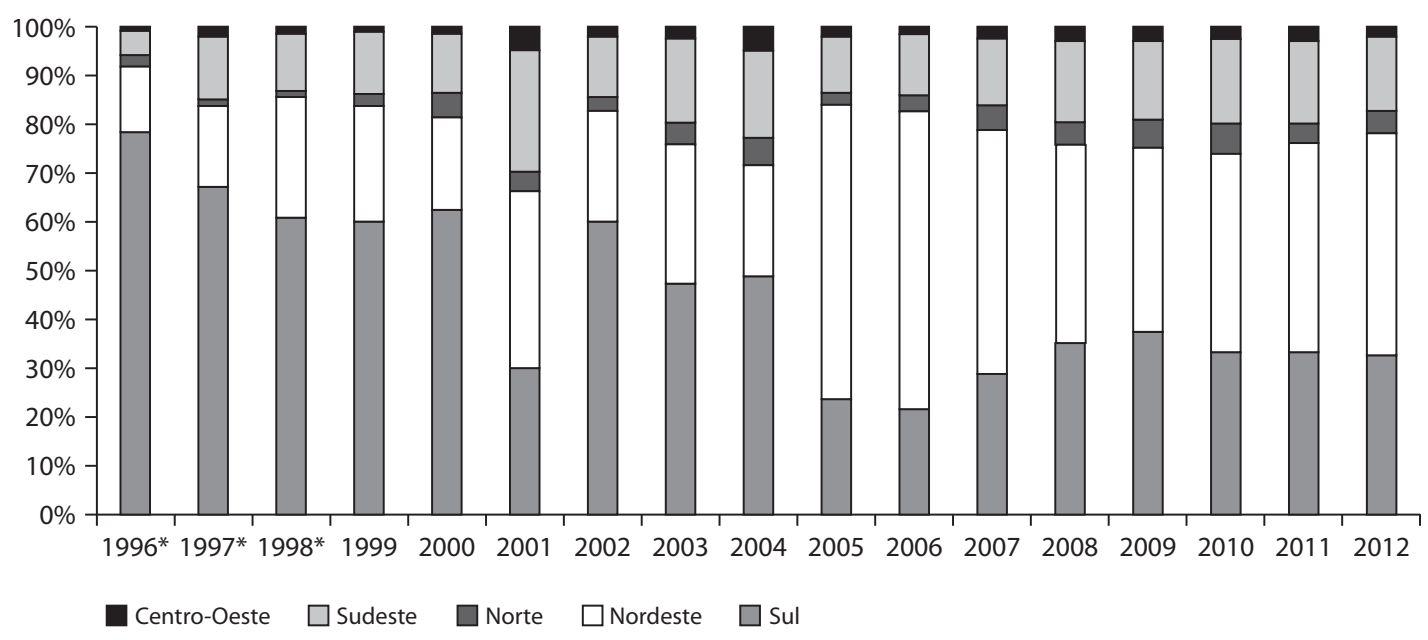

* MDA/SAF.

Fonte: Anuário Estatístico do Crédito Rural (vários anos) - Banco Central do Brasil.

Figura 5. Distribuição dos recursos aplicados pelo Pronaf entre as grandes regiões brasileiras de 1996 a 2012

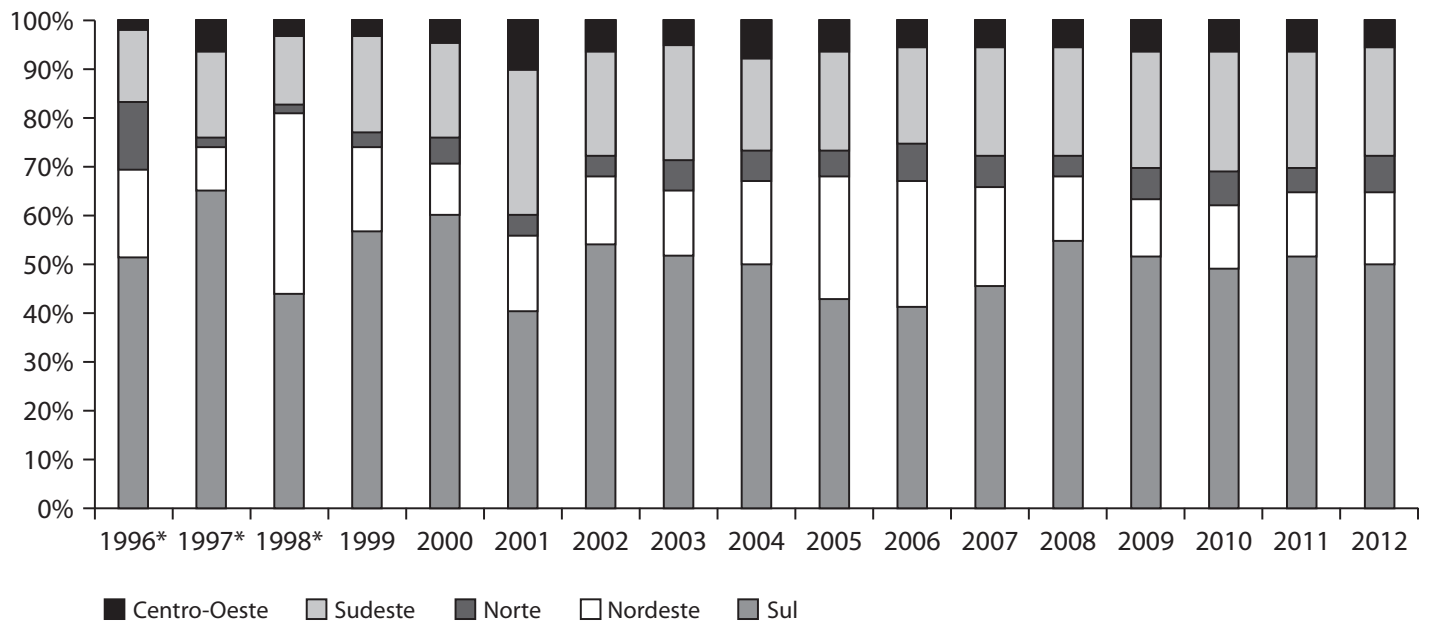

* MDA/SAF.

Fonte: Fonte: Anuário Estatístico do Crédito Rural (vários anos) - Banco Central do Brasil.

No que concerne aos recursos financeiros aplicados pelo programa (Figura 5), observa-se a predominância da região Sul em todo o período analisado, sendo que esta participação atingiu valores próximos a $60 \%$ dos recursos totais em 1997 e 2000. Em meados dos anos 2000, após várias avaliações críticas, a região meridional viu sua participação reduzida a $40 \%$ dos recursos totais, com incremento relativo da região
Nordeste, que em 2006 respondeu pelo percentual máximo de $26 \%$ dos recursos totais. No entanto, nos anos seguintes, a região Sul expandiu novamente sua participação, respondendo nos últimos cinco anos por valores próximos de $50 \%$ dos recursos totais. As regiões Norte e Centro-Oeste mantiveram seus valores relativos estáveis após a entrada do Governo Lula até 2012, com média de 6,5\%. Estes dados levam a questionar se, neste 
Figura 6. Número de contratos do Pronaf por estados brasileiros, de 1999 a 2012

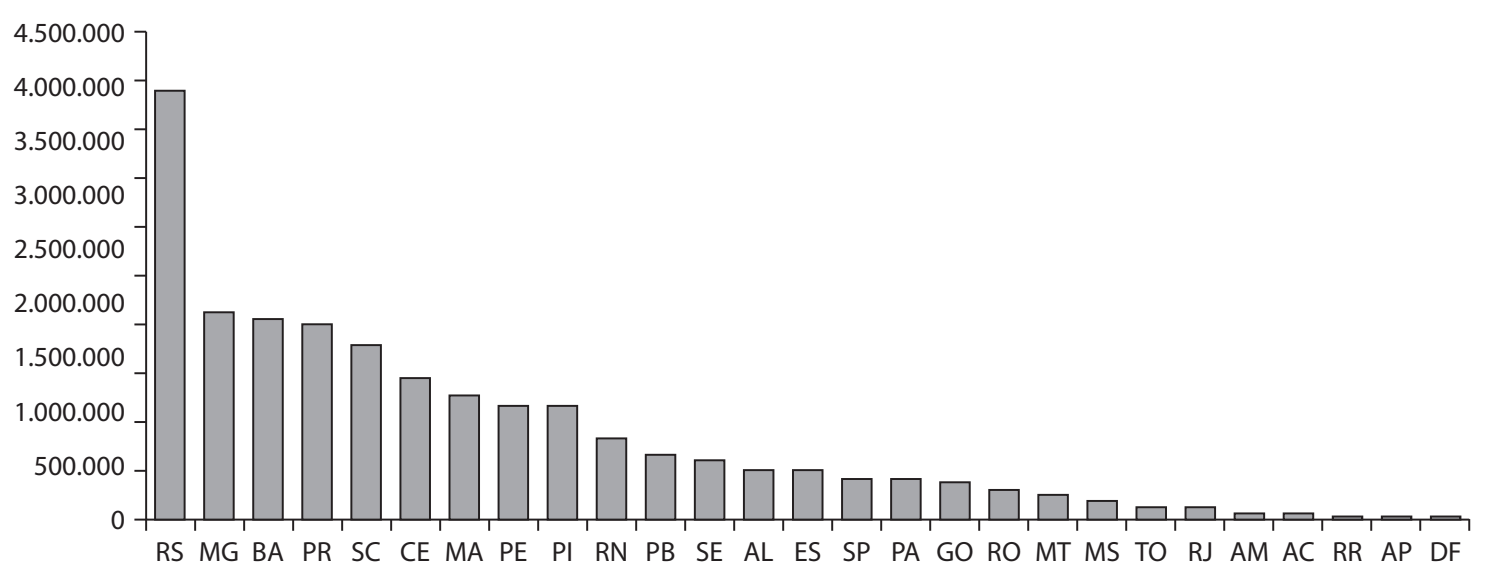

Fonte: Anuário Estatístico do Crédito Rural (vários anos) - Banco Central do Brasil.

aspecto, o Pronaf conseguiu diferenciar-se do crédito rural no período da modernização da agricultura que, conforme observaram alguns autores (DELGADO, 2010; BITTENCOURT, 2003; GRAZIANO DA SILVA, 1999; GONÇALVES NETO, 1997; KAGEYAMA et al., 1990; GUEDES PINTO, 1978), beneficiou principalmente os agricultores situados nas regiões Sul e Sudeste, onde os processos de modernização da agricultura e de industrialização da economia avançavam a "passos largos". Estaria o Pronaf reproduzindo certa "dependência de caminho" 5 do crédito rural tradicional? Esta questão será retomada também em outros aspectos a seguir.

Ao se considerar a distribuição dos contratos do Pronaf no somatório do período de 1999 a 2012 entre os estados brasileiros e Distrito Federal, observa-se a prevalência do Rio Grande

5. Este termo foi cunhado por Mahoney (2001), referindo-se ao modo como as escolhas dos atores, em momentos críticos, criam instituições que tendem a persistir e não são facilmente alteradas, orientando e condicionando o comportamento e as decisões subsequentes dos diferentes agentes envolvidos em processos concretos de produção da ruralidade. Neste sentido, ao referir-se ao Pronaf, Bittencourt (2003) evidenciou que, por ser um "apêndice" Sistema Nacional de Crédito Rural, o programa enfrenta dificuldades para operar com o público ao qual se destina, uma vez que as instituições que o operam não estão preparadas para esta função. De modo similar, Bastos (2006) também discute as dificuldades do ambiente institucional que limitam o acesso dos agricultores do Grupo B ao programa. do Sul (quase 20\%), seguido por Minas Gerais $(9,3 \%)$, Bahia $(9,0 \%)$, Paraná $(8,8 \%)$ e Santa Catarina (7,8\%) (Figura 6). Dos 20,5 milhões de contratos totais, $36 \%$ foram realizados na região Sul no período considerado. Dezessete estados e o Distrito Federal não atingiram 5\% dos contratos totais realizados entre 1999 e 2012, sendo que oito não atingiram $1 \%$. Distrito Federal, Amapá e Roraima são os estados com o menor número de contratos totais no período de 19992012, com 3.738, 9.355 e 16.906, respectivamente. Considerando-se o número de estabelecimentos de agricultores familiares nos estados e admitindo a equivalência entre um contrato do Pronaf e um estabelecimento de agricultores familiares, em 2012, os estados que atenderam o maior percentual da categoria social foram Santa Catarina $(84,4 \%)$, Rio Grande do Sul $(80,4 \%)$, Rio Grande do Norte $(70,8 \%)$, Espírito Santo $(58,4 \%)$ e Paraná $(50,9 \%)$. Por sua vez, os estados onde este percentual foi mais baixo foram: Roraima $(6,4 \%)$, Amazonas (11,5\%), Rio de Janeiro (13,6\%), Pará $(14,6 \%)$ e Mato Grosso (21,3\%).

Ao analisar a participação dos estados e do Distrito Federal nos recursos totais do Pronaf, a discrepância fica ainda mais acentuada. Observa-se que, dos R 97,6 bilhões aplicados entre 1999 e 2012, 24\% foram aplicados no Rio Grande do Sul, seguido por Paraná $(13,5 \%)$ e 
Figura 7. Recursos aplicados pelo Pronaf por estados brasileiros de 1999 a 2012

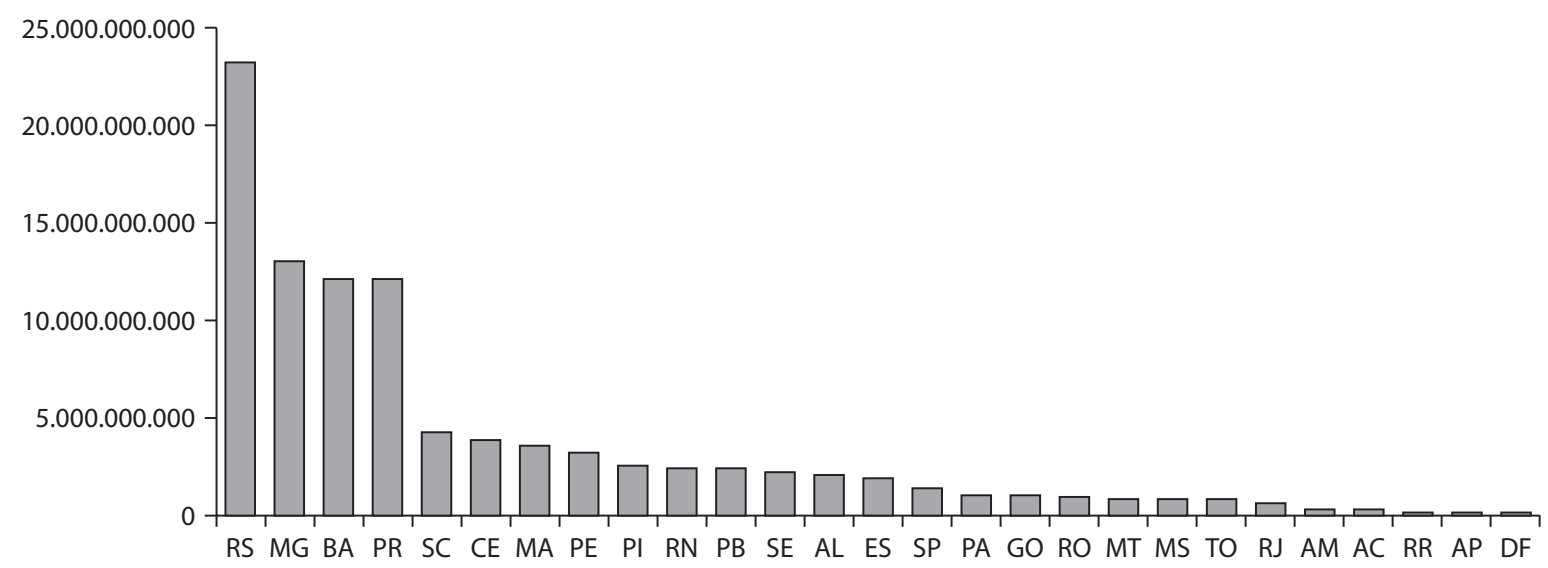

Fonte: Anuário Estatístico do Crédito Rural (vários anos) - Banco Central do Brasil.

Santa Catarina (12,4\%). Portanto, cerca de 50\% dos recursos do Pronaf no período considerado foram para a região Sul do Brasil. Em quarto lugar, destaca-se Minas Gerais $(12,4 \%)$ e em quinto distante percentualmente - está São Paulo $(4,4 \%)$. O Distrito Federal e nove estados (com exceção do Rio de Janeiro, os demais localizam-se no Norte e Nordeste) receberam, cada um, menos que $1 \%$ dos recursos totais do programa no período 1999-2012.

Complementando as informações anteriores, a Figura 8 apresenta a evolução dos valores médios dos contratos entre as grandes regiões brasileiras no período de 1996 a 2012. Embora o Centro-Oeste responda por uma participação baixa no número de contratos e nos recursos aplicados, é nesta região que se encontram os valores médios mais elevados, atingindo mais de $\mathrm{R} \$$ 20 mil em 2012. Por sua vez, a região Nordeste é onde prevalecem os valores médios mais baixos, próximos de $\mathrm{R} \$ 1.800,00$ em 2012. As demais regiões apresentam valores intermediários, oscilantes entre os anos considerados. Em seu conjunto, os resultados do gráfico corroboram com a evidência de elevação do valor médio dos contratos nos últimos anos (Figura 3). Considerando o somatório dos contratos e dos recursos totais no período 1999-2012, os estados com contratos médios mais elevados são: Mato Grosso (R\$ 11.983,56),
São Paulo (R\$ 11.518,78), Distrito Federal (R\$ 9.964,67), Goiás (R\$ 9.460,83) e Espírito Santo (R\$ 8.981,05), todos situados no Centro-Oeste e Sudeste. Por sua vez, os estados com os valores médios mais baixos são: Rio Grande do Norte (R\$1.333,98), Piauí (R\$1.337,91), Paraíba (R\$ $1.520,74)$, Sergipe (R\$ $1.543,15)$ e Ceará (R\$ $1,617,10)$, todos no Nordeste brasileiro. Os três estados do Sul apresentaram valores medianos, sendo R\$ 7.572,94 em Santa Catarina, R\$ 7.276,31 no Paraná e R\$ 5.844,07 no Rio Grande do Sul (Figura 8). Estes dados sinalizam que, se a maioria dos beneficiários do Pronaf localiza-se nas regiões Sul e Sudeste, é nesta última e no Centro-Oeste onde estão os beneficiários mais capitalizados do Pronaf.

Para avançar na discussão sobre as características dos agricultores familiares que acessam o Pronaf, a Figura 9 evidencia a distribuição dos recursos entre os grupos do programa, quais sejam: "A" referente aos assentados pelo Plano Nacional de Reforma Agrária (PNRA) ou beneficiários do Programa Nacional de Crédito Fundiário (PNCF) que não haviam contratado operação de investimento pelo Programa de Crédito Especial para a Reforma Agrária (Procera) ou que ainda não contrataram o limite de operações ou de valor de crédito de investimento para estruturação do lote; "B" correspondente aos beneficiários 
Figura 8. Evolução dos valores médios (R\$) dos contratos do Pronaf entre as grandes regiões brasileiras no período 1996 a 2012

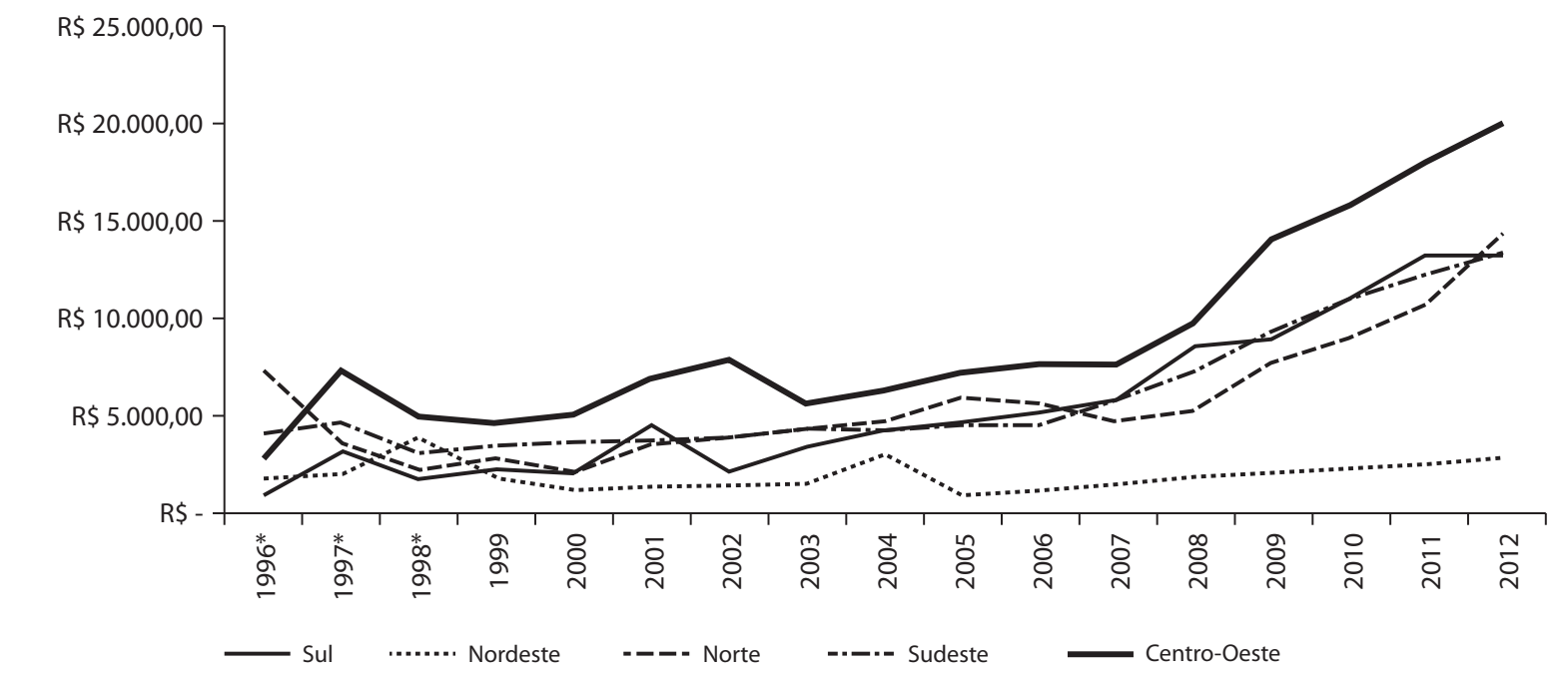

* MDA/SAF.

Fonte: Anuário Estatístico do Crédito Rural (vários anos) - Banco Central do Brasil.

cuja renda bruta familiar anual não seja superior a R 20 mil e que não contratem trabalho assalariado permanente; " $\mathrm{A} / \mathrm{C}$ " concernente aos assentados pelo PNRA ou beneficiários do PNCF que tenham contratado a primeira operação no Grupo " $\mathrm{A}$ " e não tenham contrato de financiamento de custeio, exceto no próprio Grupo "A/C"; e demais agricultores familiares, também denominado de grupo variável (BRASIL, BANCO CENTRAL DO BRASIL, 2013) ${ }^{6}$. Para este último grupo, são disponibilizadas diferentes faixas de valores de financiamento (custeio e investimento) com distintas taxas de juros.

Conforme a Figura 9, a participação do Grupo "A" e "A/C" foi significativamente reduzida ao longo do tempo, visto que respondia por 21\% em 2000 (percentual máximo atingido) e chegou a apenas 3\% do montante aplicado em 2012. Conforme Mattei (2011), nos últimos anos foi se

6. Até 2008 , no interior do grupo variável, existiam os grupos " $\mathrm{C}$ ", " $\mathrm{D}$ " e " $\mathrm{E}$ ", sendo que este último correspondia aos agricultores familiares com maior grau de capitalização, os quais podiam desfrutar de valores financiados mais elevados, com juros um pouco superiores. Estes grupos foram extintos visando simplificar a operacionalização do programa. intensificando o destino dos recursos financeiros para o segmento mais capitalizado da agricultura familiar, penalizando outros setores, particularmente aqueles assentados pela reforma agrária (categorias " $\mathrm{A}$ " e " $\mathrm{A} / \mathrm{C}$ "), que estão em processo inicial de instalação e estruturação de suas unidades de produção.

O Grupo "B", referente ao microcrédito rural, de modo geral, teve sua participação diferenciada daquela dos agricultores assentados pela reforma agrária. Os recursos aplicados cresceram ao longo dos anos, passando de 1\% em 2000 para 8\% em 2006 (ano de maior participação da região Nordeste no número de contratos do programa) e 15\% em 2012 (percentual que destoa dos valores de anos anteriores $)^{7}$. Vários fatores institucionais contribuíram para esse resultado, como: i) ampliação desta linha de crédito para todas as regiões brasileiras, visto que inicialmente se concentrava na região Nordeste, norte de Minas Gerais e norte do Espírito Santo, mesmo sem uma determinação legal para esta regionalização (SILVA MAIA

7. Como este dado destoa dos anos anteriores, é preciso precaução na análise e observação do comportamento em anos posteriores para consideraçóes mais conclusivas. 
Figura 9. Participação (\%) dos Grupos do Pronaf na distribuição dos recursos de 2000 a 2012 - Brasil

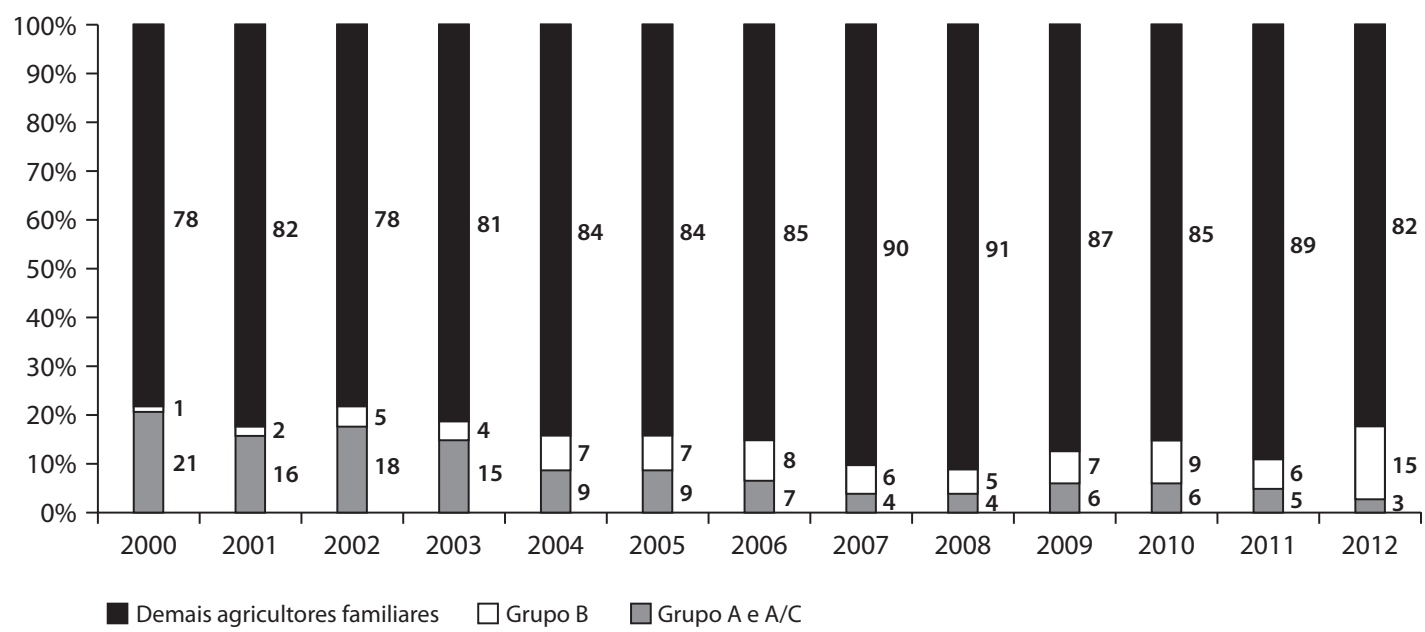

Fonte: SAF/MDA (2013 apud Aquino, 2013).

et al., 2012); ii) redução da burocracia bancária e simplificação das regras de liberação dos financiamentos, ampliando o atendimento deste segmento formado pelas famílias rurais mais pobres (MAGALHÃES e ABRAMOVAY, 2006); iii) crescimento do volume de recursos acessados por agricultor, que era de R\$ 500 em 2002 e chegou a R\$ 3.500 na safra 2013/14; iv) aumento substancial no limite de enquadramento do Grupo "B" ao longo dos anos, visto que a renda bruta anual do agricultor era de R\$ 1.500 em 2000 e alcançou R\$ 20.000 em 2013 (BRASIL, MDA, 2013); v) ampliação das fontes de financiamento, que inicialmente eram exclusivas do Orçamento Geral da União (OGU) e que, posteriormente, foram incluídos os recursos dos Fundos Constitucionais (BNDES, 2012); vi) desenvolvimento, por parte do Banco do Nordeste, de uma metodologia alternativa (chamada de "Agroamigo") para a operacionalização do Grupo "B", que inclui a presença de um assessor de crédito que estabelece uma relação personalizada com cada agricultor, o que reduziu consideravelmente as taxas de inadimplência dos financiamentos (ABRAMOVAY, 2008; CAZELLA e BÚRIGO, 2009); vii) prioridade do governo federal na erradicação da miséria no Brasil, fortalecendo as políticas públicas de apoio às camadas mais pobres da população (BNDES, 2012).
Apesar do avanço do Pronaf para o Grupo "B", foram os agricultores mais capitalizados (agora chamados de "Grupo Variável") que acessaram massivamente os recursos do Pronaf no período em análise, sendo que, nos últimos anos, os percentuais nunca foram menores que $80 \%$ - atingindo o valor máximo de 91\% em 2008 (Figura 9). Esta concentração se mantém ao longo dos anos porque, assim como aconteceu no Grupo " $\mathrm{B}$ ", houve importantes transformações institucionais no Pronaf que acabaram favorecendo este estrato de produtores, como a flexibilização das condições financeiras, aumento da renda para fins de enquadramento dos agricultores, a simplificação das condições de acesso, diversificação das fontes de financiamento, renegociação de dívidas etc. (DELGADO, LEITE e WESZ JUNIOR, 2010; GRISA e WESZ JUNIOR, 2010; DESCONSI, 2012).

Estes dados destoam muito da estratificação da agricultura familiar entre os grupos do Pronaf realizada pelo IBGE no último Censo Agropecuário, sendo que os agricultores familiares enquadrados nos grupos " $A$ " e " $B$ " perfazem $67,56 \%$ dos estabelecimentos da agricultura familiar brasileira, enquanto que os demais agricultores familiares respondem por $32,44 \%$ dos estabelecimentos. Dados de Mattei (2011) para o ano agrícola 2007/2008 indicavam que os agri- 
cultores familiares dos grupos " $\mathrm{D}$ " $\mathrm{e}$ " $\mathrm{E}$ ", correspondentes aos produtores mais estruturados e capitalizados entre a categoria social, detinham participação de 53\% dos recursos do programa. Estas informações corroboram a afirmação, já realizada em outros estudos (AQUINO et al., 2011; MATTEI, 2011), de que o Pronaf tem beneficiado principalmente as unidades familiares de produção em melhores condições socioeconômicas.

Não obstante o conjunto de mudanças que foram realizadas no programa desde a sua criação, visando incorporar uma diversidade maior de agricultores familiares, alguns segmentos mais vulneráveis economicamente encontram limitações para efetivar sua participação. Portanto, nem todas as mudanças institucionais no Pronaf apresentam êxito em sua operacionalização ou foram suficientes para a incorporação destes segmentos $^{8}$. Conforme ressalta Mattei (2011, p. 13), “[...] após 14 anos de existência do programa, nem todas as inovações que foram introduzidas acabaram resultando em uma política que contemple efetivamente todos os segmentos ligados ao setor da produção familiar", reproduzindo também nas características do público beneficiário certa dependência de trajetória e seletividade observada no crédito rural tradicional executado nas décadas de modernização da agricultura brasileira9. O crescimento do Pronaf no Grupo "B" pode sinalizar possíveis mudanças, que são importantes, mas ainda insuficientes se for considerado o peso deste grupo no conjunto da agricultura familiar brasileira. Além disso, a redução da participação dos assentados da reforma agrária preocupa pelo fato de que são unidades de produção em processo inicial de instalação e estruturação.

8. A própria criação dos grupos do Pronaf resultou do reconhecimento da diversidade no interior da agricultura familiar e da necessidade de tratá-la de acordo com suas especificidades. No entanto, como visto acima, atender esta diversidade persiste como desafio importante para o programa.

9. É importante destacar que esta seletividade observada no crédito rural tradicional se mantém até o momento atual, como argumenta Aquino (2013).

\section{Produtivismo ou diversidade? As finalidades e os cultivos financiados pelo Pronaf}

Ao longo dos anos é possível observar a crescente participação do crédito de investimento (agrícola e pecuário) no Pronaf em âmbito nacional (Figuras 10 e 11). No período inicial do programa havia uma supremacia do financiamento para custeio, cobrindo quase $90 \%$ dos contratos e mais de $80 \%$ dos recursos. A partir de 2000, observa-se um incremento na participação do investimento, que ocorre até 2006, quando há uma pequena redução em termos relativos. A partir da criação da Linha Mais Alimentos ${ }^{10} \mathrm{em}$ 2008, há uma retomada do crescimento da modalidade investimento, o que está, provavelmente, relacionado com as melhores condições de crédito, que ocorreu tanto em termos de prazos de pagamento como de juros cobrados ${ }^{11}$. Em 2012, $63 \%$ dos contratos e 53\% dos recursos do Pronaf foram aplicados em investimento, sinalizando para um possível incremento na capitalização da agricultura familiar.

10. A Linha Pronaf Mais Alimentos, denominada também de "Mais Alimentos", foi criada em 2008 em um contexto de crise internacional dos preços dos alimentos. Os objetivos do Mais Alimentos são "financiar a modernização das propriedades familiares", fortalecer e aumentar a produção de alimentos da agricultura familiar e, ao mesmo tempo, dar impulso à indústria nacional de máquinas e equipamentos afetada com a crise financeira internacional, a qual foi deflagrada de modo mais intenso a partir de setembro de 2008 (BRASIL, MDA, 2010, p.57). Os financiamentos contemplam atualmente projetos associados à produção de arroz, feijão, milho, mandioca, trigo, hortigranjeiros, leite, castanha, caprino, ovinos, café, gado para abate, suínos e aves. Podem ser financiadas máquinas, equipamentos, aquisição de animais, correção de solos, formação de pomares, armazenagem, melhoria genética etc. Existem cerca de 3.600 itens cadastrados no Mais Alimentos, contemplando produtos como tratores, colheitadeiras, motocultivadores e equipamentos para a produção de leite.

11. Para elucidar, cita-se que, desde o Plano Safra da Agricultura Familiar 2011/2012, o juro máximo para crédito de investimento situa-se em $2 \%$ ao ano, sendo que, para financiamentos até R\$10.000, este percentual é de 1\%. Ademais, desde este Plano Safra, o prazo de pagamento foi ampliado de oito para dez anos (BRASIL, MDA, 2011). 
Figura 10. Finalidade dos contratos do Pronaf (\%) de 1999 a 2012 - Brasil

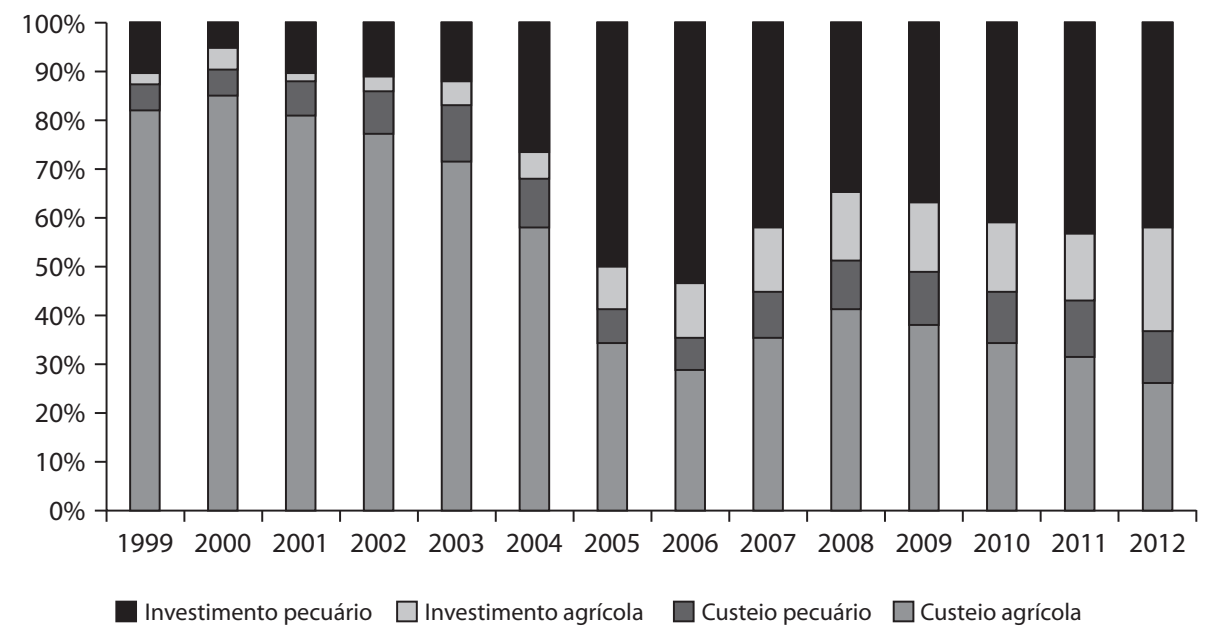

Fonte: Anuário Estatístico do Crédito Rural (vários anos) - Banco Central do Brasil.

Figura 11. Finalidade dos recursos do Pronaf (\%) de 1999 a 2012 - Brasil

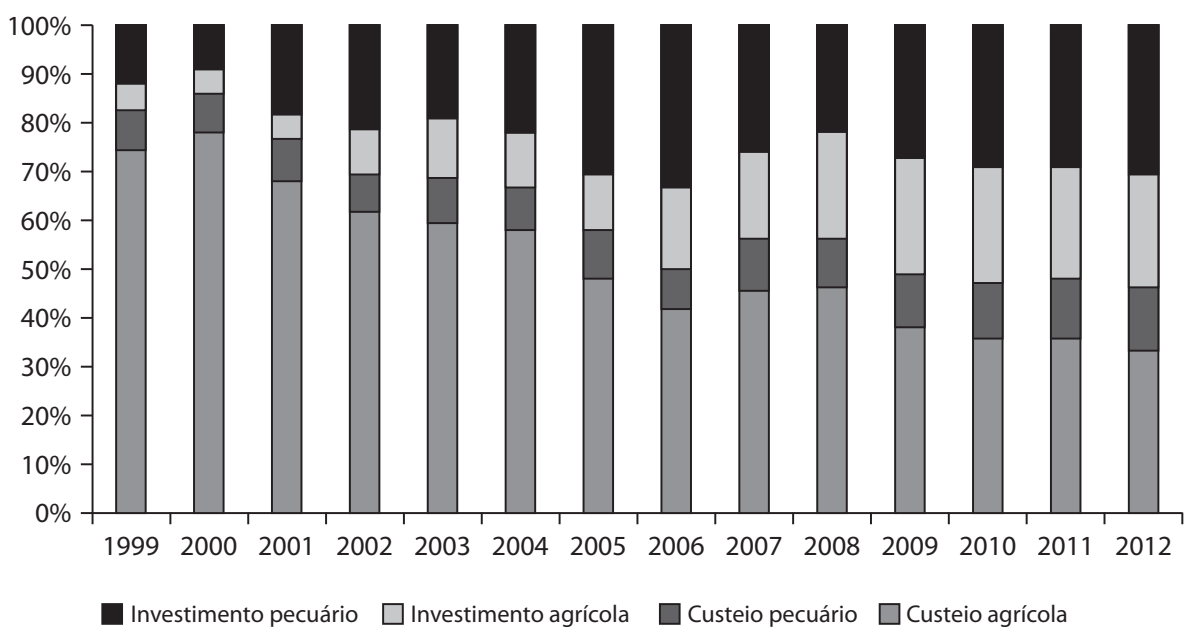

Fonte: Anuário Estatístico do Crédito Rural (vários anos) - Banco Central do Brasil.

Ao aprofundar a análise do crédito de investimento (pecuário e agrícola), observa-se o grande aumento dos recursos aplicados na compra de "máquinas e equipamentos" (que passaram de 3\% em 2000 para $25 \%$ em 2012) e na aquisição de veículos, o que remete ao início do Programa Mais Alimentos, quando o financiamento para estas modalidades chegou a um terço do total do crédito de investimento (Figura 11). As metas do Plano Safra 2008/2009, que lançou o Mais Alimentos, eram comercializar 60 mil tratores e 300 mil máqui- nas e implementos agrícolas até 2010 (BRASIL, MDA, 2008). Ainda que por ora não tenha atingido estas cifras, informações divulgadas em abril de 2012 indicavam a comercialização de 300 colheitadeiras desde 2008, 4 mil veículos de transporte de cargas e 44 mil tratores, superando de forma expressiva os menos de 7 mil tratores adquiridos nos 10 anos anteriores à vigência desta linha do Pronaf (BRASIL, PRESIDÊNCIA DA REPÚBLICA, 2012). Ainda que o crédito de investimento seja uma necessidade para a agricultura familiar e 
é reivindicado pelas organizações da categoria social (FETRAF-BRASIL, 2011; 2010; CONTAG, 2008; GRISA, 2012), é preciso analisar se o Mais Alimentos tem atingido seus objetivos, notadamente no que concerne ao aumento da produção de alimentos e à segurança alimentar e nutricional no Brasil. A esta análise poderia ser acrescentada a indagação se esta mudança no Pronaf não pode se traduzir em uma acentuação do caráter produtivista do programa, dada sua ênfase na comercialização de tratores e outros maquinários agrícolas. Ao adquirir um financiamento elevado referente a este fim, o agricultor familiar tende a intensificar a produção comercial e aumentar a escala para cumprir seus "compromissos" com o banco, não raro investindo na especialização produtiva, na produção de commodities e no uso de insumos químiCOs (GRISA e WESZ JUNIOR, 2010; WILKINSON, 1986). Nas palavras de Mattei (2011, p. 9), “[...] deve-se questionar se essa lógica de 'modernização da agricultura familiar' não poderia levar à construção de um processo de produção monocultor e excludente da mesma maneira que ocorreu com a agricultura comercial tradicional em períodos anteriores".

Ao longo das safras também foi ampliado o peso dos projetos para o "melhoramento das explorações", e "outras aplicações" perderam espaço. A "aquisição de animais", "formação de culturas permanentes" e "animais de serviço" foram modalidades que mantiveram certa estabilidade em seu percentual nos últimos dez anos. Apesar das variações ao longo das safras, as três principais modalidades são "aquisição de animais", "máquinas e equipamentos" e "melhoramento das explorações", que no período recente passaram a responder por aproximadamente $80 \%$ do crédito para investimento (Figura 12).

Ao analisar especificadamente o crédito de custeio agrícola para todo o País, observa-se que os principais produtos de lavoura financiados no período de 1999 a 2012 foram milho, soja, café e fumo (Figura 13). O milho e a soja, que se consolidaram nas duas primeiras posições, respondem desde 2001 por mais de $50 \%$ dos recursos aplicados pelo Pronaf no custeio de lavouras (em 2002 e 2003, os dois produtos alcançaram mais de $60 \%$ ). Se somados os recursos aplicados no café (cultivo que apresentou importante crescimento em número de contratos e recursos no período em análise), este valor atinge cerca de $70 \%$ dos recursos aplicados no custeio de lavouras. Apesar de o milho ser o principal cultivo, ele tem perdido participação relativa, assim como o fumo, feijão,

Figura 12. Distribuição dos recursos do crédito de investimento (pecuário e agrícola) do Pronaf de acordo com suas finalidades de 1999 a 2012 - Brasil

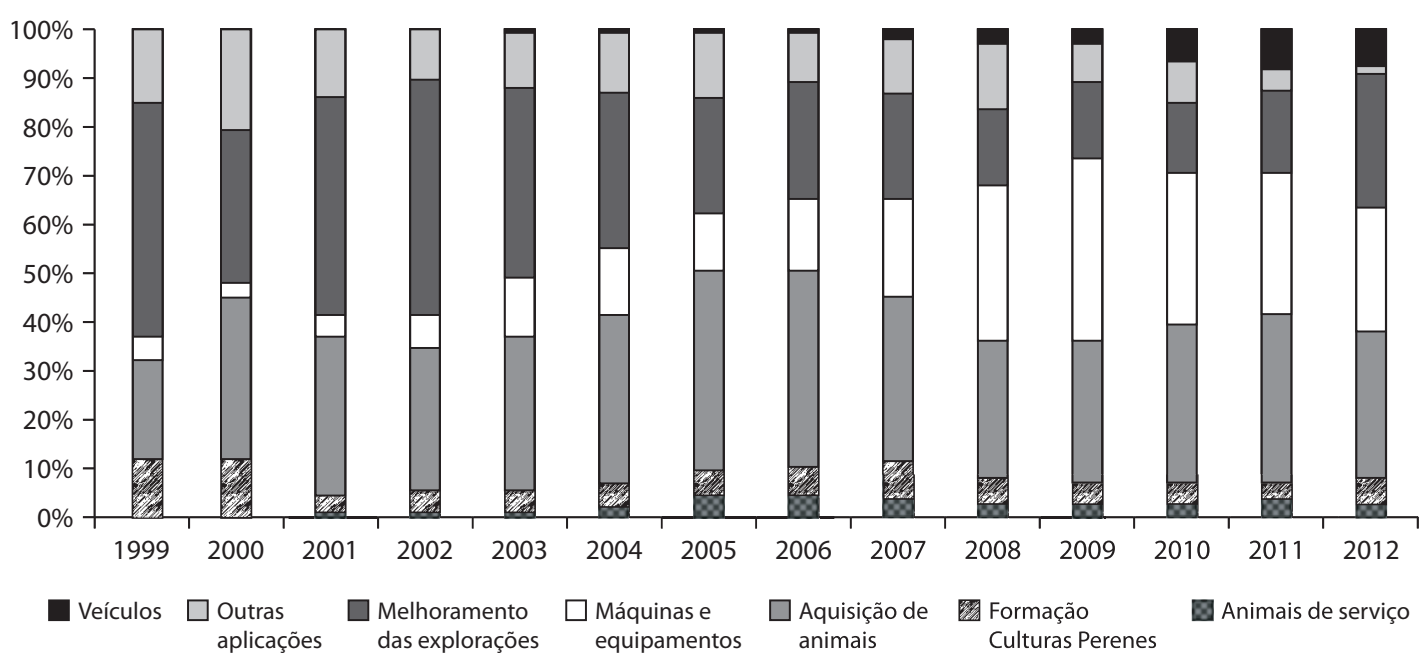

Fonte: Anuário Estatístico do Crédito Rural (vários anos) - Banco Central do Brasil. 
Figura 13. Distribuição dos recursos do crédito de custeio para produtos de lavoura do Pronaf de 1999 a 2012- Brasil

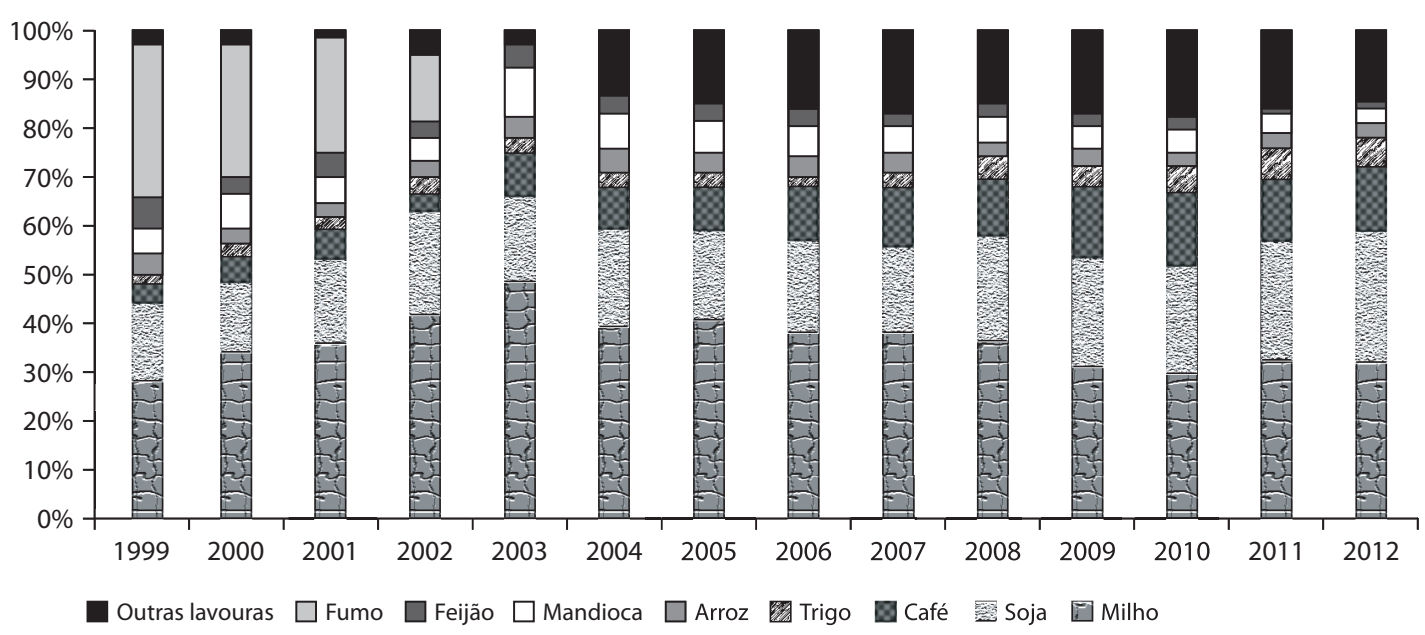

Fonte: Anuário Estatístico do Crédito Rural (vários anos) - Banco Central do Brasil.

Figura 14. Distribuição dos recursos do crédito de custeio para produtos de lavoura do Pronaf (soma dos valores de 1999 a 2012) - Brasil

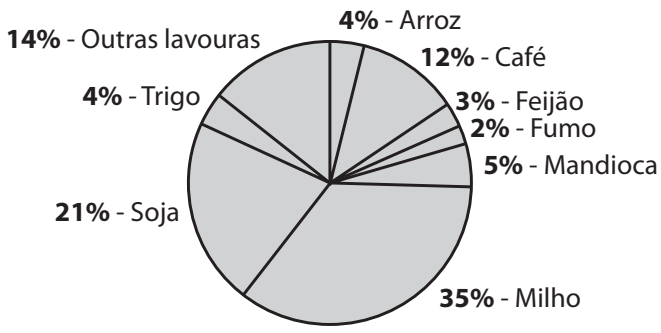

Fonte: Anuário Estatístico do Crédito Rural (vários anos) - Banco Central do Brasil

mandioca e arroz. Nos últimos anos tem crescido o item "outras lavouras"12, o que sinaliza a possibilidade de ampliação das atividades financiadas e, portanto, a diversificação da carteira do Pronaf.

12. Categoria incluída pelo Conselho Monetário Nacional no Anuário Estatístico do Crédito Rural em 2002. A categoria "outras lavouras" engloba os demais cultivos financiados pelo Pronaf. Não há informações disponíveis no Anuário Estatístico do Crédito Rural que possibilitem identificar os cultivos que fazem parte da categoria, nem a participação de cada um no total citado. Entretanto, é muito provável que se tratem de cultivos menos tradicionais para o crédito rural e com importantes variações regionais. A própria classificação do Bacen já é indicativa do interesse em mensurar somente os produtos tidos como principais, não sendo possível perceber o peso do cacau, laranja, hortigranjeiros etc.
A Figura 14 confirma a importância do milho $(35 \%)$, da soja $(21 \%)$ e do café $(12 \%)$ como principais cultivos financiados pelo crédito de custeio para lavouras no somatório do período 19992012. De modo geral, pode-se dizer que estes produtos, devido às suas características de produção e comercialização, restringem os "espaços de manobra" das unidades familiares de produção. Trata-se de lavouras geralmente associadas à monocultura, a escalas de produção, à crescente "externalização" da atividade produtiva e à dependência das grandes empresas do sistema agroindustrial (PLOEG, 2008, 2006). As características desses cultivos sinalizam um caráter produtivista do Pronaf, como também já indicaram vários 
estudos (AQUINO e SCHNEIDER, 2010; SHIKI, 2010; SABOURIN, 2009; TOLEDO, 2009; IBASE, 2006; MATTEI, 2006; GAZOLA e SCHNEIDER, 2005; KAGEYAMA, 2003; NEUMAN e FERREIRA, 2002), reproduzindo certa seletividade em termos de produtos financiados pelo Sistema Nacional de Crédito Rural.

No entanto, esta análise em âmbito nacional do crédito de custeio pode camuflar os processos regionais empreendidos pelo Pronaf. As Figuras 15 e 16 apresentam os dois principais cultivos financiados pelo programa em cada estado e no Distrito Federal, tanto em termos de número de contratos como de recursos aplicados na soma do período em análise (1999 a 2012). Algumas observações chamam a atenção rapidamente: é notória a diversidade de produtos financiados no País, que pode ser observada pela variedade de cores nos mapas (Figuras 15 e 16), e a importância que determinados produtos assumem em certas regiões e estados, como a mandioca no Amapá (que responde por $78,9 \%$ dos contratos e $65,3 \%$ dos recursos do custeio de lavouras no total do período 1999-2012) e no Maranhão (49\% dos contratos e $58,4 \%$ dos recursos); o café no Espírito Santo (85,4\% dos contratos e 79,1\% dos recursos) e em Minas Gerais $(55,8 \%$ dos contratos e $58,5 \%$ dos recursos); o arroz em Roraima (31,5\% dos contratos); o feijão na Bahia (30\% dos contratos e $22,7 \%$ dos recursos); a cana-de-açúcar em Pernambuco (36,9\% dos contratos e $28 \%$ dos recursos); o algodão na Paraíba (25,6\% dos contratos e 16,3\% dos recursos); a soja em Mato Grosso do Sul (30\% dos contratos e $50,9 \%$ dos recursos); o milho no Paraná (49,4\% dos contratos e o 40,1\% dos recursos); e o fumo em Santa Catarina (10,9\%). Chama a atenção igualmente a importância da categoria "outras lavouras", apontando para a possível diversidade de produtos financiados em alguns estados, como Amazonas (onde respondeu por $46,7 \%$ dos contratos e $82,3 \%$ dos recursos), Rio de Janeiro $(70,5 \%$ dos contratos e $78,9 \%$ dos recursos), São Paulo (42,4\% dos contratos e 47,7\% dos recursos), Rio Grande do Norte (26,9\% dos contratos e $49,8 \%$ dos recursos), Paraíba (26,3\% dos contratos e $57,8 \%$ dos recursos), Pernambuco
(30,9\% dos contratos e 48,5\% dos recursos) e Pará (24,5\% dos contratos e $31 \%$ dos recursos). Estes dados podem minimizar a constatação de um viés produtivista do Pronaf, demonstrando a variedade de cultivos financiados nos diferentes estados, bem como o elevado peso que alguns produtos exercem em certas regiões ${ }^{13}$.

No entanto, não é possível ignorar que mais de $30 \%$ dos contratos e $40 \%$ dos recursos foram, historicamente, aplicados na região Sul do Brasil (Figuras 4 e 5). Além disso, no Rio Grande do Sul e no Paraná, o milho e a soja respondem por quase $80 \%$ dos contratos e mais de $70 \%$ dos recursos aplicados no custeio de lavoura no período 19992012, sendo que, nestes contextos, trata-se de cultivos associados à monocultura, à especialização produtiva e ao uso intensivo de insumos cuja origem em grande medida é externa aos estabelecimentos rurais. Também não é possível ignorar que mais de 55\% dos recursos nacionais do custeio de lavouras no total do período de 19992012 foram aplicados em milho e soja (Figura 13). Contudo, trata-se de um produtivismo territorializado do Pronaf, marcado principalmente pela presença do milho e da soja nas regiões Sul e Centro-Oeste (Figuras 15 e 16). No Norte, no Nordeste e em alguns estados da região Sudeste é notável a participação de cultivos como a mandioca, feijão, arroz e outras lavouras, produtos que podem estar diretamente associados com a promoção da segurança alimentar e nutricional dos agricultores familiares. O próprio milho, que no Sul e Centro-Oeste está vinculado a um contexto de especialização produtiva, no Nordeste, por exemplo, é um produto fundamental para o consumo familiar e dos animais, normalmente cultivado em consórcio e que não rompe com a diversidade de atividades agrícolas dos agricultores familiares.

13. O que não exime a necessidade de refletir sobre o viés setorial do programa e o imperativo de este incorporar o debate sobre ruralidade, considerando as múltiplas atividades, papéis e inter-relações que envolvem o rural contemporâneo (WANDERLEY e FAVARETO, 2013; DELGADO et al., 2013; AQUINO e SCHNEIDER, 2010; WANDERLEY, 2009). 


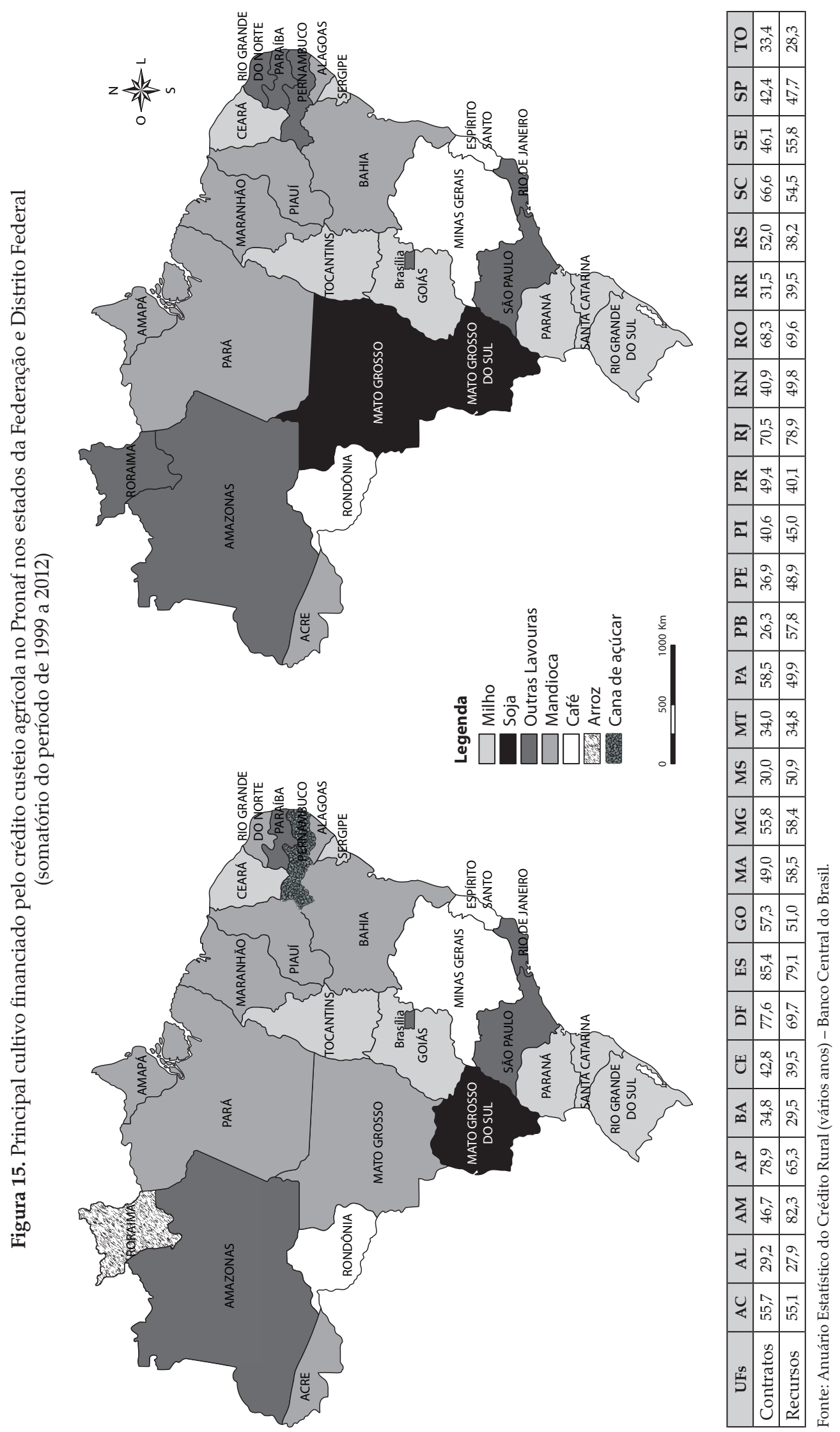




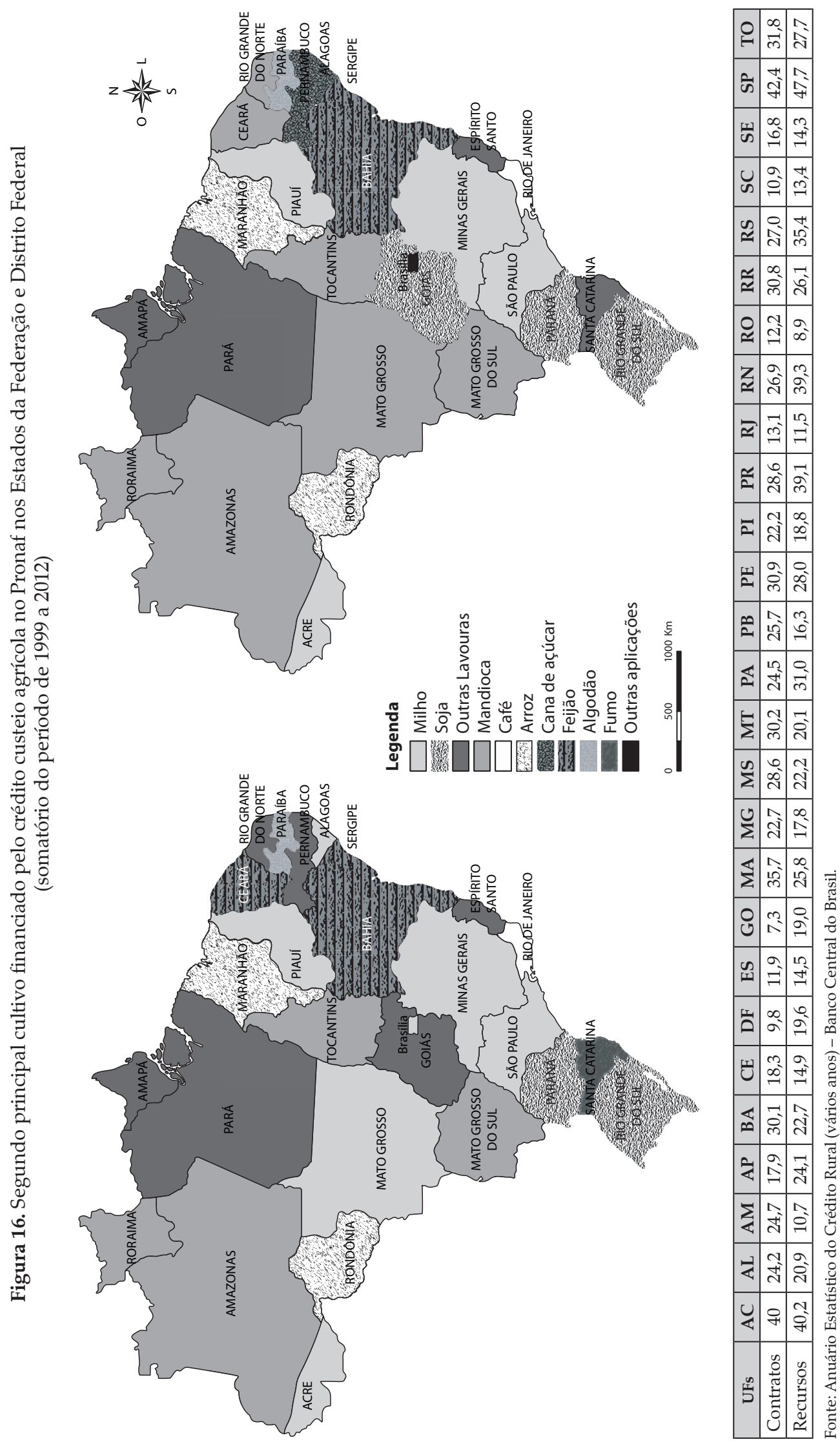


Os dados para os estados e o Distrito Federal agregados para o período 1999-2012, discutidos acima, contribuem para relativizar o produtivismo nacional do Pronaf, mas também não permitem observar as dinâmicas e as transformações regionais ocorridas neste período. Ao analisar-se o comportamento dos produtos de lavoura financiados pelo Pronaf em três períodos distintos (1999-2003; 2004-2008; 2009-2012) ${ }^{14}$, observam-se certas mudanças importantes no perfil produtivo de alguns estados, que precisariam ser melhor investigadas em outros estudos.

No Rio Grande do Sul e no Paraná, o milho foi o principal produto de lavoura financiado pelo crédito de custeio (contratos e recursos) desde o início da série até 2008, quando, a partir de então, a soja tornou-se o principal produto financiado em termos de recursos. Em Santa Catarina, o fumo foi o principal produto financiado pelo crédito de custeio (contratos e recursos) até 2001, quando cedeu espaço para o milho, que cresceu sua participação nos recursos de custeio de lavoura do Pronaf aplicados no estado, mas que vem reduzindo sua participação em termos de número de contratos a partir de 2004. Movimento similar é observado com o arroz no estado, que também reduziu o número de contratos e aumentou sua participação nos recursos aplicados de 2004 em diante. Já a soja vem incrementando sua participação no Pronaf (contratos e recursos) no estado desde o início da série (ainda que respondendo por menos de 10\% dos contratos e dos recursos do custeio de lavouras em 2012) (BANCO CENTRAL DO BRASIL, 2013).

Em Goiás, observa-se redução expressiva no número de contratos e recursos para arroz entre 2004 (2.104 contratos e R\$ 8,4 milhões) e 2012 (3 contratos e R\$ 153 mil) e crescimento da soja, sendo que, em 2011 e 2012, este foi o principal

14. Estes três momentos referem-se a importantes intervalos do Pronaf: 1999-2003 foi um período de maior estabilidade nos recursos aplicados; em 2004-2008 há uma expansão no montante de recursos e aumento o número de contratos; em 2009-2012 ocorre a implementação e consolidação do Mais Alimentos, que teve forte impacto no perfil dos financiamentos (intensificando a modalidade investimento) e no aumento do valor médio dos contratos. cultivo financiado em termos de recursos, com, respectivamente, $35,45 \%$ e $45,42 \%$ do total de recursos aplicados nos custeio de lavouras. Desde 2004/2005, a produção de milho vem reduzindo sua participação tanto em termos de contratos como de recursos em Goiás. Em Mato Grosso do Sul, desde 2006, a soja é o principal cultivo (em contratos e recursos) financiado pelo crédito de custeio para lavouras, sendo que, em 2011 e 2012, este produto respondeu por $50 \%$ dos contratos e mais de 55\% dos recursos aplicados nesta categoria. Em Mato Grosso, esta predominância da soja ocorreu nos dois últimos anos, sendo que, em 2011 , este produto respondeu por $37,4 \%$ dos contratos e $71,6 \%$ dos recursos do custeio de lavoura, e em 2012 estes percentuais se elevaram, respectivamente, para $55,3 \%$ e $84 \%{ }^{15}$ (BANCO CENTRAL DO BRASIL, 2013).

Em São Paulo, destaca-se a produção de "outras lavouras", que desde 2005 tem acrescido em termos de recursos aplicados, mas também é importante registrar o crescimento dos recursos aplicados em cana-de-açúcar e café, os quais passaram de $\mathrm{R}$ \$1,4 milhão e $\mathrm{R}$ \$37,6 mil em 1999, respectivamente, para $\mathrm{R} \$ 39,01$ milhões e R\$ 14,5 milhões em 2012 (o número de contratos para estes cultivos também apresentou elevação; contudo, nos últimos três anos, apresentou leve redução). No Rio de Janeiro, como visto acima, o financiamento de "outras lavouras" também é responsável por grande parte dos contratos e dos recursos do custeio de lavouras, sendo que os números para ambos foram crescentes até 2010, quando, a partir de então, se observa importante redução (em 2010 foram realizados 5.570 contratos para "outras lavouras" com total de R\$ 51,3 milhões e, em 2012, estes valores foram reduzidos para R \$2.651 e R \$29,7 milhões, respectivamente).

Em Rondônia e Roraima, observa-se redução importante no número de contratos para pro-

15. Chama a atenção o aumento da participação da soja no custeio de lavouras nos últimos anos nos estados do Sul e Centro-Oeste. O comportamento do mercado internacional da soja pode ter contribuído neste sentido, pois os principais momentos de crescimento dos recursos aplicados nesta oleaginosa foram em períodos de importantes aumentos no preço (2002 a 2004; 2007 a 2008; 2010 a 2012). 
dução de arroz, passando, respectivamente, de 3 mil (2004) e 362 (2005) para 31 e 5 (2012). Esta queda importante na participação do arroz também é observada no Piauí e Tocantins, sendo que, neste último, em 2003, o número de contratos era de 1.250 e os recursos eram da ordem de $\mathrm{R} \$$ 4,3 milhões e, em 2012, estes números passaram para 56 e R\$ 915 mil. Chama a atenção também a perda de importância do algodão (em número de contratos e total de recursos) em vários estados do Nordeste, como Bahia, Ceará, Paraíba, Piauí e Rio Grande do Norte. No Piauí, foram realizados 852 contratos para algodão em 2005, totalizando R\$ 1,3 milhão e, desde então, não foi realizado mais nenhum contrato (exceto 2008, quando apenas um foi efetivado). A cana-de-açúcar destaca-se nos estados de Alagoas e Pernambuco, onde se observou redução no número de contratos desde 2009/2010, ainda que se mantenha em relevância em termos de participação nos recursos do custeio de lavouras. Por exemplo, o número de contratos em Pernambuco passou de quase 4 mil em 2008 para 262 em 2012. O feijão perdeu importância em número de contratos e recursos em Alagoas, Ceará, Piauí e Sergipe, principalmente no período 2009-2012. Para ilustrar, cita-se o caso de Alagoas, onde, em 2003, foram realizados quase 6.500 contratos e foram acessados R\$ 9,13 milhões, enquanto que, em 2012, foram realizados dois contratos, totalizando pouco mais de R\$ 3.200. O feijão foi o principal produto financiado pelo Pronaf custeio para lavouras no período 1999-2003 em Alagoas, tanto em número de contratos quanto em recursos. O financiamento de "outras lavouras" em termos de recursos tem sido crescente no Maranhão e no Amazonas. Em Pernambuco, desde 2007, o número de contratos e recursos para "outras lavouras" vem sendo reduzido (BANCO CENTRAL DO BRASIL, 2013).

\section{Considerações finais}

A trajetória do Pronaf aponta para importantes avanços ao longo dos seus quase 20 anos, como o aumento dos recursos aplicados, flexibilização das condições financeiras, ampliação dos beneficiários, simplificação das condições de acesso, expansão para novas regiões etc. Entretanto, existem alguns resultados que se mantêm, como a concentração nas commodities (principalmente milho, soja e café) e nos agricultores familiares mais capitalizados das regiões Sul, Sudeste e Centro-Oeste. Nesse sentido, pode-se dizer que há certa semelhança e reproduções de características do crédito rural brasileiro do período da modernização da agricultura, que privilegiou os grandes e médios produtores, espacialmente localizados no Centro-Sul do País e com produção destinada à exportação (BITTENCOURT, 2003; LEITE, 2001).

Portanto, cabe questionar se o programa continua fazendo "mais do mesmo" (segue incentivando o modelo de desenvolvimento do período de modernização da agricultura) e "mais com os mesmos" (o apoio aos agricultores familiares já com maior familiaridade com o sistema bancário, ainda que também alijados das políticas de modernização da agricultura nas décadas de 1960-70), como geralmente aparece nos estudos do Pronaf e destacado por Gazolla e Schneider $(2013,2005)$. Por um lado, esses elementos são corroborados quando são analisados os dados nacionais, pois, de fato, há grande concentração dos recursos e dos contratos no Sul e Sudeste do Brasil, onde é majoritário o acesso dos agricultores mais capitalizados (aqui se somam também os agricultores familiares do Centro-Oeste) e para os cultivos de soja, milho e café (Figuras 13 e 14). Ao espacializar os dados do Pronaf (dados estaduais), a continuidade do "mais do mesmo" é evidente na região Sul do Brasil, onde o milho e a soja foram os principais produtos financiados pelo crédito de custeio agrícola no somatório do período 1999-2012. Contudo, nesta análise especializada, também é evidenciado que existem outras faces do programa que precisam ser consideradas, visto que ocorrem financiamentos (ainda que com participação minoritária nos recursos totais do Pronaf) de atividades e para atores que, talvez, nunca antes compunham o foco das políticas de crédito rural. 
Em relação ao fazer "mais do mesmo", a região Norte pode ser um exemplo de como tem havido inovações importantes, pois lá ocorrem financiamentos a produtos característicos da agricultura familiar, como a mandioca, o feijão, o arroz e "outras lavouras". Portanto, não se trata de commodities que dependem de um grande volume de insumos externos ao estabelecimento e que, depois de colhida, seguem, em grande medida, para exportação. Em vez disso, são alimentos que tradicionalmente foram produzidos pelos agricultores e que, quando não consumidos pela família, seguem para o mercado local e regional.

No que se refere ao fazer "mais para os mesmos", é preciso considerar que o Grupo "B" do Pronaf incorpora um público historicamente excluído das políticas agrícolas, em especial aquelas de crédito rural. Embora os possíveis incrementos que possam ser observados no período recente, o percentual de acesso do grupo persiste desproporcional diante do número de agricultores familiares enquadrados no Grupo B. Além disso, tem havido ao longo dos últimos anos um movimento de expansão dos contratos nas regiões com menor participação do Pronaf, como é o caso do Nordeste e Norte, que aumentaram 320\% e $217 \%$, respectivamente, de 2002 a 2012. Ao averiguar a taxa de crescimento dos contratos no Sul para o mesmo período, se percebe que os valores foram modestos (aumento de apenas 14\%), enquanto o Sudeste e o Centro-Oeste apresentaram resultado próximo a $150 \%$.

Estes elementos apontam que as especificidades e a diversidade de formas da agricultura familiar brasileira estão sendo, paulatinamente, aproximadas ao Pronaf ${ }^{16}$. Contudo, muitos avanços precisam ocorrer para que o Pronaf rompa

16. No sentido de "quem são" os agricultores familiares do Pronaf, caberia ainda investigar - o que não foi possível de ser realizado neste trabalho - o atendimento da diversidade da categoria social para além dos grupos do programa ("A", "A/C", "B" e demais), abarcando elementos de gênero, geração e segmentos sociais (quilombolas, extrativistas, faxinalenses, indígenas etc.). Os comportamentos das linhas do programa (Pronaf Jovem, Mulher, Agroecologia, Floresta etc.) podem ser importantes indicadores iniciais nesta investigação. com certa "dependência de caminho" do crédito rural tradicional. A consolidação do programa enquanto política de desenvolvimento rural efetiva ainda depende deimportantes avanços operacionais e institucionais (AQUINO e SCHNEIDER, 2010; BASTOS, 2006; BITTENCOURT, 2003; ABRAMOVAY e VEIGA, 1999). Existem obstáculos burocráticos impostos pelo sistema bancário que dificultam o acesso de agricultores familiares com níveis de renda inferiores ou que apresentem projetos de financiamento não convencionais; geralmente os agricultores familiares mais capitalizados estão mais organizados e informados, o que favorece o acesso destes ao programa; não raro, a assistência técnica e a extensão rural apresentam dificuldades ou não estão preparadas para trabalhar com os segmentos menos capitalizados ou com projetos não convencionais, prevalecendo interpretações setoriais e produtivistas sobre o rural e a agricultura familiar; a desarticulação entre as políticas públicas, notadamente entre as políticas de incentivo à produção (crédito e assistência técnica) e as políticas de comercialização (Programa de Aquisição de Alimentos PAA e Programa Nacional de Alimentação Escolar - PNAE, por exemplo), limitam o potencial do Pronaf em promover mudanças no padrão de desenvolvimento agrícola; embora apresentem críticas ao modelo de produção hegemônico, as reivindicações das organizações sindicais da agricultura familiar geralmente concernem a demandas operacionais do programa (redução de juros, ampliação dos recursos, limites financiáveis etc.), o que pode confluir para a reprodução institucional do mesmo (GRISA, 2012); e é preciso retomar o debate sobre ruralidade no programa, considerando a necessidade de este incorporar as múltiplas dimensões e atividades que compreendem o rural brasileiro contemporâneo.

\section{Referências bibliográficas}

ABRAMOVAY, R. Alcance e limites das finanças de proximidade no combate à inadimplência: o caso do Agroamigo. Texto para discussão, n. 10. São Paulo, 2008. 
ABRAMOVAY, R. e VEIGA, J.E. Novas instituições para o desenvolvimento rural: o caso do Programa Nacional de Fortalecimento da Agricultura Familiar (PRONAF). Brasília/DF: IPEA, 1999. (Texto para Discussão, 641).

AQUINO, J. R. Financiamento da agricultura brasileira: cenário atual e perspectivas. In: $51^{o}$ Congresso da Sociedade Brasileira de Economia e Sociologia Rural (Sober). Belém, 2013 (Power-point).

AQUINO, J. R. et al. Dimensão e localização do público potencial do PRONAF "B" no Brasil: uma análise a partir do Censo Agropecuário 2006. In: XLIX Congresso da Sociedade Brasileira de Economia, Administração e Sociologia Rural, 2011, Belo Horizonte (MG). Anais... Sober, 2011.

AQUINO, J. R. e SCHNEIDER, S. 12 anos da política de crédito do PRONAF no Brasil (1996-2008): uma reflexão crítica. In: VIII Congresso Latinoamericano de Sociologia Rural, 2010, Porto de Galinhas, Anais... Porto de Galinhas (PE): ALASRU, 2010.

BANCO CENTRAL DO BRASIL. Anuário Estatístico do Crédito Rural. Disponível em: <http://www.bcb.gov. br/?RELRURAL > . Acesso em: set. 2013.

BASTOS, F. Ambiente institucional no financiamento da agricultura familiar. São Paulo (SP): Editora Polis Ltda, 2006.

BELIK, W. PRONAF: avaliação da operacionalização do programa. In: CAMPANHOLA, C. e GRAZIANO DA SILVA, J. O novo rural brasileiro: políticas públicas. Jaguariúna (SP): EMBRAPA Meio Ambiente, 2000. p. 93-115.

BIANCHINI, V. O Programa Nacional de Fortalecimento da Agricultura Familiar - PRONAF e a sustentabilidade da agricultura no Vale do Ribeira - Paraná. Tese (Doutorado em Meio Ambiente e Desenvolvimento) - Programa de Pós-Graduação em Meio Ambiente e Desenvolvimento (MADE/UFPR). Curitiba (PR), 2010.

BITTENCOURT, G. A. Abrindo a caixa-preta: o financiamento da agricultura familiar no Brasil. Dissertação (Mestrado em Desenvolvimento Econômico, Espaço e Meio Ambiente) - Programa de Pós-graduação em Desenvolvimento Econômico, Espaço e Meio Ambiente (IE/UNICAMP). Campinas (SP), 2003.

BNDES. Pronaf B: evolução e metodologias. Informativo técnico AGRIS, n. 2, p. 1-16, 2012.

BRASIL, BANCO CENTRAL DO BRASIL. Manual do crédito rural, jul. 2013. (atualização em 18/07/2013).

BRASIL. MDA. Plano safra da agricultura familiar 2011/2012: para quem gosta de notícias boas, este é um prato cheio. Brasília (DF): MDA, 2013.
. Plano safra da agricultura familiar 2011/2012: a agricultura familiar alimenta o Brasil que cresce. Brasília (DF): MDA, 2011.

- Um novo Brasil rural. Ministério do Desenvolvimento Agrário 2003/2010. Brasília: MDA, 2010.

Mais Alimentos: um plano da agricultura familiar para o Brasil. Plano safra da agricultura familiar 2008/2009. Brasília: MDA, 2008.

Resultados do Pronaf. Disponível em: http:// www.mda.gov.br/ Acesso em: set. 2007. 2007.

BRASIL. PRESIDÊNCIA DA REPÚBLICA. Programa Mais Alimentos terá estande na Agrishow 2012 para ampliar inclusão de agricultores familiares. Imprensa. 25/04/2012. Disponível em: <http://www2.planalto. gov.br/imprensa/noticias-de-governo/programamais-alimentos-tera-estande-na-agrishow-2012-paraampliar-inclusao-de-agricultores-familiares $>$. Acesso: 10 mai. 2012.

CAZELLA, A. A. e BÚRIGO, F. L. Inclusão financeira e desenvolvimento rural: a importância das organizações territoriais. Política e Sociedade, v. 8, n. 14, p. 301-331, 2009.

CONFEDERAÇÃO NACIONAL DOS TRABALHADORES NA AGRICULTURA (CONTAG). Grito da Terra Brasil 2008: Pauta de Reivindicações. Brasília (DF): CONTAG, FETAGs e STTR, 2008.

DELGADO, N. G. O papel do rural no desenvolvimento nacional: da modernização conservadora dos anos 1970 ao Governo Lula. In: DELGADO, N.G. Brasil rural em debate: coletânea de artigos. Brasília (DF): CONDRAF/ NEAD, 2010, p.28-78.

DELGADO, N. G. et al. Concepções de ruralidade e politicas públicas na América Latina e Europa: análise comparativa de países selecionados. v. 21, Brasília (DF): IICA, 2013. Série Desenvolvimento Rural Sustentável.

DELGADO, N. G., LEITE, S. e WESZ JUNIOR, V. Nota técnica: produção agrícola. Rio de Janeiro (RJ), 2010.

DESCONSI, C. Análise qualitativa das estratégias econômicas presentes em unidades familiares beneficiárias do Microcrédito Rural (Pronaf). Relatório de Consultoria. Brasília/MDA, 2012.

DIEESE. Estatísticas do meio rural 2010-2011. São Paulo: DIEESE; NEAD; MDA, 2011.

FRANÇA, C. V., DEL GROSSI, M. D. e MARQUES, V. P. M. A. M. Agricultura familiar no Brasil e o Censo Agropecuário 2006. Brasília (DF): MDA, 2009.

FEDERAÇÃO NACIONAL DOS TRABALHADORES E TRABALHADORAS NA AGRICULTURA FAMILIAR 
(FETRAF-Brasil). Pauta de reivindicações da VII Jornada nacional de luta da agricultura familiar. Brasília (DF): FETRAF-Brasil, 2011.

. Pauta de reivindicações da VI Jornada nacional de luta da agricultura familiar. Brasília (DF): FETRAF-Brasil, 2010.

GAZOLLA, M. e SCHNEIDER, S. Qual Fortalecimento da Agricultura Familiar? Uma análise do Pronaf crédito de custeio e investimento no Rio Grande do Sul. Revista de Economia e Sociologia Rural, v. 51, p. 45-68, 2013.

. As duas "caras" do PRONAF: produtivismo ou fortalecimento da produção para autoconsumo? In: Congresso brasileiro de economia, administração e sociologia rural, 43, 2005, Ribeirão Preto (SP), Anais... Ribeirão Preto/SP: SOBER, 2005.

GONÇALVES NETO, W. Estado e agricultura no Brasil: política agrícola e modernização econômica brasileira, 1960-1980. São Paulo (SP): Hucitec, 1997.

GRAZIANO DA SILVA, J. Tecnologia e agricultura familiar. Porto Alegre (RS): Editora da UFRGS, 1999.

GRISA, C. Políticas públicas para a agricultura familiar no Brasil: produção e institucionalização das ideias. Tese (Doutorado de Ciências Sociais em Desenvolvimento, Agricultura e Sociedade) - Programa de Pós-graduação de Ciências Sociais em Desenvolvimento, Agricultura e Sociedade (CPDA/UFRRJ). Rio de Janeiro (RJ), 2012.

GRISA, C. e WESZ JUNIOR, V. Políticas públicas para a agricultura familiar: entre avanços e desafios. Boletim do OPPA, n. 3, 2010.

GUANZIROLI, C. E. Construcción de políticas agrarias en Brasil: el caso del PRONAF. Agenda social (UENF), v. 3, p. 2-32, 2009.

Pronaf dez anos depois: resultados e perspectivas para o desenvolvimento rural. Revista de Economia e Sociologia Rural, v. 45, p. 301-328, 2007.

GUEDES PINTO, L. C. Notas sobre a política de crédito rural. In: Reunião da Sociedade Brasileira para o Progresso da Ciência, 3, 1978, Anais... São Paulo (SP): SBPC, 1978.

INSTITUTO BRASILEIRO DE ANALISES SOCIAIS E ECONOMICAS (IBASE). Relatório PRONAF: resultados da etapa Paraná. Rio de Janeiro (RJ): IBASE, 2006.

INSTITUTO BRASILEIRO DE GEOGRAFIA E ESTATÍSTICA. Censo agropecuário 2006. Rio de Janeiro (RJ): 2009.

KAGEYAMA, A. Produtividade e renda na agricultura familiar: efeitos do PRONAF-crédito. Agricultura, v. 50, n. 2, p. 1-13, 2003.
KAGEYAMA, A. et al. O novo padrão agrícola brasileiro: do complexo rural aos complexos agroindustriais. In: DELGADO, G. Agricultura e políticas públicas. Brasília (DF): IPEA, v.1, 1990, p. 113-223.

LEITE, S. P. Padrão de financiamento, setor público e agricultura no Brasil. In: LEITE, S. P. (Org.). Políticas Públicas e Agricultura no Brasil. Porto Alegre, Ed. da UFRGS, 2001, p. 53-94.

MAGALHÃES, R. e ABRAMOVAY, R. Acesso, uso e sustentabilidade do Pronaf B. Consultoria Plural, 2006.

MAHONEY, J. Path-dependent explanations of regime change: Central America in comparative perspective. Studies in comparative international development, v. 6, n. 1, 2001.

MATTEI, L. Evolução do crédito do PRONAF para as categorias de agricultores A e A/C entre 2000 e 2010. In: Congresso da Sociedade Brasileira de Economia, Administração e Sociologia Rural, 49, 2011, Belo Horizonte (MG), Anais... Belo Horizonte (MG): SOBER, 2011.

PRONAF 10 anos: mapa da produção acadêmica. Brasília (DF): MDA, 2006.

. Impactos do PRONAF: análise de indicadores. Brasília (DF): MDA/NEAD, 2005.

NEUMAN, P. S. e FERREIRA, P. E. R. Análise do PRONAF como política pública de promoção do desenvolvimento da agricultura familiar: o caso do município de Três Palmeiras-RS. In: Congresso da Associação Latino-Americana de Sociologia Rural, 6, 2002, Porto alegre (RS), Anais... Porto Alegre (RS): ALASRU, 2002.

PLOEG, J. D. V. D. Camponeses e impérios alimentares: luta por autonomia e sustentabilidade na era da globalização. Porto Alegre (RS): Editora da UFRGS, 2008.

. O modo de produção camponês revisitado. In: SCHNEIDER, S. A diversidade da agricultura familiar. Porto Alegre (RS): Editora da URGS, 2006, p. 13-54.

SABOURIN, E. Camponeses do Brasil: entre a troca mercantil e a reciprocidade. Rio de Janeiro (RJ): Garamont, 2009.

SCHNEIDER, S., CAZELLA, A. e MATTEI, L. Histórico, caracterização e dinâmica recente do Pronaf-Programa Nacional de Fortalecimento da Agricultura Familiar. In: SCHNEIDER, S., SILVA, M. K. e MARQUES, P. E. M. (Orgs.) Políticas públicas e participação social no Brasil rural. Porto Alegre (RS): Editora da UFRGS, 2004. p. 21-49.

SHIKI, S. Política agrária e conservação da biodiversidade no Brasil. Estudos sociedade e agricultura, v. 18, n. 2, p. 288-316, 2010. 
SILVA MAIA, G. B. et al. O Pronaf B e o financiamento agropecuário nos Territórios da Cidadania do semiárido. Revista do BNDES, n. 37, p. 177-216, 2012.

SOUZA, P.M. et al. Análise da evolução do valor dos financiamento do Pronaf-Custeio (1999-2010): número, valor médio e localização geográfica dos contratos. Revista de Economia e Sociologia Rural, v. 51, n. 2, p. 237-254, 2013.

TOLEDO, E. N. B. O PRONAF em Salvador das Missões: contradições de uma política de crédito. Dissertação (Mestrado em Desenvolvimento Rural) - Programa de Pós-Graduação em Desenvolvimento Rural (PGDR/ UFRGS). Porto Alegre (RS), 2009.

TONNEAU, J. P., AQUINO, J. R. e TEIXEIRA, O. A. Modernização da agricultura familiar e exclusão social: o dilema das políticas agrícolas. Cadernos de ciência $\mathcal{E}$ tecnologia, v. 22, n. 1, p. 67-82, 2005.

WANDERLEI, M. N. B. O mundo rural como um espaço de vida: reflexões sobre a propriedade da terra, agricultura familiar e ruralidade. Porto Alegre: Editora da UFRGS, 2009.

WANDERLEI, M. N. B. e FAVARETO, A. A singularidade do rural brasileiro: as implicações para as tipologias territoriais e a elaboração de políticas públicas. v. 21, Brasília (DF): IICA, 2013. Série Desenvolvimento Rural Sustentável.

WILKINSON, J. O Estado, a agroindústria e a pequena produção. São Paulo (SP)/Salvador (BA): Hucitec/ CEPA-BA, 1986. 
